\title{
Molecular taxonomy, phylogeny and biogeography of the Niphargus tatrensis species complex (Amphipoda, Niphargidae) in Austria
}

\author{
Fabio Stoch ${ }^{1}$ (D) Erhard Christian ${ }^{2} \cdot$ Jean-François Flot ${ }^{1,3}$ (D) \\ Received: 18 February 2020 / Accepted: 1 September 2020 / Published online: 6 October 2020 \\ (C) Gesellschaft für Biologische Systematik 2020
}

\begin{abstract}
The Niphargus tatrensis species complex, entirely subterranean, has a wide distribution range extending from Southern Poland to Austria and Slovenia. Because of its large and confusing morphological variability, it was subdivided into several 'forms', four of which described from Austrian caves. To shed light on this chaotic situation, we sampled the type localities of all described species and forms in the complex, as well as additional sites in Austria, and used nuclear (28S, ITS) and mtDNA (COI) sequences to revise its taxonomy. Phylogenetic analysis confirmed that the Niphargus tatrensis species complex is monophyletic. Applying four species delimitation methods to the COI dataset converged on the presence of four species in Austria; by contrast, the same methods applied to ITS concurred with a haploweb analysis of this marker in distinguishing only three species in the country. Reconstruction of ancestral ranges suggested that the Austrian clade originated in Eastern Europe. Bayesian biogeographical analyses revealed a complex history of lineage divergence and secondary contact during the Pleistocene climatic fluctuations, possibly responsible for the higher variability of COI in comparison with ITS. Based on the above, we conclude that only three valid species are present in Austria: considering all described forms as subspecies, two of them are elevated to species rank whereas one new species is formally described and illustrated.
\end{abstract}

Keywords Species delimitation methods $\cdot$ Haploweb $\cdot$ Groundwaters $\cdot$ Caves $\cdot$ Bayesian biogeographic analysis

\section{Introduction}

During the last decade, several papers have been dedicated to the unresolved and incomplete taxonomy of the genus Niphargus Schiødte, 1849 (see Fišer et al. 2008; EsmaeiliRineh et al. 2015; Delić et al. 2020 and bibliography cited therein). The genus, with over 425 described species (Horton et al. 2019) distributed in the Western Palearctic, is

Electronic supplementary material The online version of this article (https://doi.org/10.1007/s13127-020-00462-z) contains supplementary material, which is available to authorized users.

Fabio Stoch

fabio.stoch@ulb.be

1 Evolutionary Biology \& Ecology, Université libre de Bruxelles (ULB), C.P. 160/12, Avenue F.D. Roosevelt 50,

1050 Brussels, Belgium

2 Institut für Zoologie, Universität für Bodenkultur Wien, Gregor Mendel Str. 33, 1180 Wien, Austria

3 Interuniversity Institute of Bioinformatics in Brussels (IB), Brussels, Belgium almost completely tied to groundwaters, except for a few species recorded from surface lakes (Karaman and Ruffo, 1986), streams (Copilaş-Ciocianu et al. 2017) and peat bogs (Fišer et al. 2014).

The problems of exhaustively reviewing the taxonomy of the genus are partly due to the scarcity of material collected. In the first place, the subterranean habitats are difficult to access (especially caves, which may require advanced speleological techniques), most species have restricted distribution ranges (although exceptions exist: Trontelj et al. 2009; Fišer et al. 2010; Copilaş-Ciocianu et al. 2018) and sometimes species are known from single or few localities difficult to trace using old taxonomic literature and museum labels. Second, the morphotaxonomy of this group is very unsatisfactory (Fišer et al. 2008; Trontelj et al. 2009): morphological characters are highly homoplastic (Fišer et al. 2008, 2010), and differences between species are weak while intraspecific variation can be high (Delić et al. 2020), requiring the examination of an unpractically large, usually unattainable number of specimens from each locality. Although molecular techniques have been found to be powerful tools for complementing the traditional morphotaxonomy of Niphargus (Flot 2010, Brad et al. 2015), 
a number of shortcomings may cast a shadow on the taxonomic value of recent molecular revisions: (i) a lack of sequences obtained from topotypic specimens, (ii) identification errors in attributing sequences to the described morphospecies, (iii) chromatograms of low quality and/or improperly basecalled (notably in case of heterozygous individuals) and (iv) an uncritical use of species delimitation methods in describing cryptic species, considering that they can yield different results, especially if based on single loci (Dellicour and Flot 2015, 2018).

Trontelj and Fišer (2009) suggested that taxa living in environments with strong directional selection (such as subterranean waters) might be subject to crypsis more frequently, and widely distributed morphospecies can possibly represent complexes of cryptic species (Trontelj et al. 2009). The detection of a high number of cryptic species over the whole Niphargus distribution range (Eme et al. 2018) confirmed this hypothesis, suggesting that a complete revision of this genus will be a very demanding task in terms of time and resources. Fišer et al. (2018) considered it 'technically challenging and unlikely to be completed in the near future', suggesting that 'local revisions represent a more realistic way forward'. Recent examples of geographically restricted revisions can be found, among others, for the Middle East (EsmaeiliRineh et al. 2015) and Switzerland (Fišer et al. 2018), and further ones are urgently needed.

To evaluate the suitability of molecular techniques to solve the complex and confusing taxonomic problems hindering Niphargus taxonomy, we focused here on the Niphargus tatrensis species complex. This species group, as already pointed out in a tentative morphological revision and cladistic analysis by Fišer et al. (2010), is important for several reasons: (i) Niphargus tatrensis Wrześniowski, 1888 (type locality: Zakopane, Tatra Mountains, southern Poland) is one of the first established Niphargus species names, hence important for the stability of nomenclature; (ii) the range of this taxon is very wide (Southern Poland, Slovakia, the Czech Republic, Hungary, Austria and Slovenia), making it suitable to test the hypothesis of Trontelj et al. (2009) that widely distributed morphospecies are usually complexes of cryptic species; and (iii) $N$. tatrensis described species, subspecies and 'forms' are highly variable morphologically (Fišer et al. 2010), making it a particularly good case study. This morphological diversity is reflected in its subdivision into seven forms (Schellenberg 1935, 1937, 1938) of unclear taxonomic validity, four of which (f. lunzensis, f. lurensis, f. oetscherensis and f. salzburgensis) were described from Austrian caves, while other three were described from Hungary (f. aggtelekiensis), Czech Republic (f. schneebergensis) and Poland (f. reyersdorfensis). In the catalogue of the extant cave animals of Austria (Strouhal and Vornatscher 1975), N. tatrensis is by far the amphipod species with the highest number of entries. All this makes Austria an ideal country for addressing a regional revision.
Taxonomists have disagreed on the status of the described forms of Niphargus tatrensis. Jersche (1963) rejected three forms from the eastern Alps, whereas Micherdziński (1956) recognised only a 'North-Alpine' form, a 'Silesian' form and a 'Tatra' form. Forms are not recognised (being considered of infrasubspecific rank) by the International Code of Zoological Nomenclature (ICZN). However, forms described before 1961 and meeting precise requirements (Lingafelter and Nearns 2013) can be considered subspecies, and their names become nomenclaturally available. Fišer et al. (2010) stated that Schellenberg's forms were never cited as subspecies in any paper before 1985, and for this reason, their names were unavailable (under ICZN, 1999 edition, Article 45.6.4). Consequently, these forms were not included in the World Register of Marine Species (WoRMS; Horton et al. 2019).

Based on a thorough cladistic analysis of morphological characters, Fišer et al. (2010) recognised as valid only two species (N. tatrensis from Poland, the Czech Republic and Slovakia and N. aggtelekiensis Dudich, 1932 from Austria, Slovakia and Hungary). Moreover, they added to the species complex a third species (N. scopicauda Fišer et al. 2010) from Slovenia. Subsequently, Hudec and Mock (2011) studied the distribution of $N$. tatrensis and N. aggtelekiensis in Slovakia, identifying some 'transition forms' as presumptive hybrids.

A further element of uncertainty concerns the phylogenetic affinities of the $N$. tatrensis group. It was originally established (as 'group tatrensis') by Straškraba (1972) and included $N$. tatrensis 'with its subspecies' together with other six species; the latter were subsequently excluded from the group by Fišer et al. (2010). Straškraba (1972) pointed out possible affinities with three Italian species (N. speziae Schellenberg 1936, N. romuleus Vigna Taglianti 1968 and doubtfully $N$. pedemontanus Ruffo 1937), subsequently included by Karaman (1993) in N. stygius Schiødte, 1849. The actual phylogenetic affinities of the $N$. tatrensis group remained unclear until recently, when more complete multimarker trees showed that the $N$. tatrensis species complex is a very isolated clade within the genus Niphargus (Delić et al. 2020).

As a satisfactory taxonomic revision of the Niphargus tatrensis species complex could not be accomplished using a detailed cladistic analysis of morphological characters (Fišer et al. 2010), we gathered ample material including topotypic specimens of all described species and forms within this complex and turned to DNA sequencing of three gene fragments (a fragment of the nuclear ribosomal 28S, the complete ITS region and Folmer's COI fragment of the mitochondrial cytochrome $c$ oxidase subunit I) to assess the distinctiveness and diversity of this widely distributed species group. We reconstructed the phylogeny and evolutionary history of this species complex and applied several molecular species delimitation methods to define the taxonomic diversity of the group in Austria, the focal area. Moreover, following the key provided 
by Lingafelter and Nearns (2013), we formally established the available names of the described forms, providing a solid basis for a stable nomenclature of the whole species complex. Finally, our combined morphological and molecular analyses led us to formally describe a new species from southern Styria.

\section{Material and methods}

\section{Sampling sites}

Samples were collected from 34 sites (caves, mines and springs) throughout the wide range of the Niphargus tatrensis species complex, with a focus on Austria (Fig. 1; Table 1). Cave-dwelling specimens were collected by two of the authors (F.S. and E.C.), by hydrobiologists and by several expert speleologists with appropriate techniques for cave progression (mentioned by name in Tab. 1). Spring specimens were mainly collected by Reinhard Gerecke during field surveys in the Austrian National Park Gesäuse. Most specimens were handnetted or, in easily accessible places, captured in baited traps.

All type localities of the seven different forms reported by Schellenberg (1937) were sampled, as well as the type locality of $N$. aggtelekiensis and springs as close as possible to the type locality of $N$. tatrensis (an undisclosed well in Zakopane: Wrześniowski 1888). Topotypic specimens of N. speziae and $N$. romuleus were also included, because these species were formerly considered as related to the $N$. tatrensis species complex. Type localities were carefully checked in the original literature, and their current names are given in Table 1. Samples were stored in $96 \%$ EtOH immediately after collection.

\section{Nomenclatorial analyses and morphological analysis}

All the collected specimens were attributed to their respective species or forms using the original descriptions in Wrześniowski (1888), Dudich (1932), Schellenberg (1935) and Fišer et al. (2010). Schellenberg (1935) described the forms as items in an identification key; drawings and complete morphological descriptions were published 2 years later (Schellenberg 1937), then amended by Fišer et al. (2010). Schellenberg's (1935) identification key was used to identify the Austrian specimens. Finally, following the key provided by Lingafelter and Nearns (2013), the name availability of the described forms was established.

Morphological identification and dissection of selected specimens were performed under a Zeiss Stemi SV11 stereomicroscope. Specimens to be deposited in collections were stored in $75 \% \mathrm{EtOH}$ with $10 \%$ glycerine added; the material was deposited in the Natural History Museum of Vienna (Austria). Appendages of selected specimens were mounted on slides in Faure's medium and sealed with nail polish.
Drawings and measurements were performed under a Zeiss Axioskop microscope equipped with a drawing tube $(\times 50$ $400)$ and Nomarski's DIC. Drawings were scanned and digitally inked using Coleman's (2003, 2009) techniques using the programs Adobe Illustrator $\odot$ and Graphic $\odot$ in a Mac environment.

\section{DNA extraction, PCR amplification and sequencing}

One or two pereopods were used for DNA extraction, and the remaining parts of each specimen were stored in $96 \% \mathrm{EtOH}$ at $-20{ }^{\circ} \mathrm{C}$ at the Universite libre de Bruxelles, Belgium. Extraction of genomic DNA from 1 to 2 pereopods (depending on the size of the specimen) was performed using the NucleoSpin ${ }^{\circledR}$ Tissue kit of Macherey-Nagel, following the manufacturer's protocol. The eluted DNA was stored at $4{ }^{\circ} \mathrm{C}$ until amplification then long-term stored at $-20^{\circ} \mathrm{C}$. A fragment (between 977 and 979 bp long) of the nuclear 28S rRNA gene and a 658-bp fragment of the mitochondrial cytochrome $c$ oxidase subunit I (COI) were amplified in all specimens. Selected specimens from Austria were used to amplify the complete internal transcribed spacer (ITS) region (together with flanking portions of the $18 \mathrm{~S}$ and $28 \mathrm{~S}$ genes). Primers were the same as used by Verovnik et al. (2005) and Flot et al. (2010a), except those for the COI region, where the best amplification success was given by the primers used by Astrin and Stüben (2008). A list of primers and PCR amplification protocols used in this study is available in Table S1. Direct sequencing was performed using the same primers as for amplification and/or using internal primers (see Flot et al. 2010a); PCR products were sent for bidirectional Sanger sequencing to Genoscreen (Lille, France).

Chromatograms were inspected, assembled and cleaned using Sequencher 4 (Gene Codes). Some ITS chromatograms contained double peaks, as expected in the case of lengthvariant heterozygotes (see Flot et al. 2006); these individuals were phased using the web tool Champuru (Flot 2007). Some COI sequences reported in a previous dataset (Eme et al. 2017b) had already been deposited in GenBank, while all newly obtained sequences were deposited in GenBank in 2020 (accession numbers reported in Table S2). Three 28S and three COI sequences already available for members of the $N$. tatrensis species complex (Delić et al. 2020) were retrieved directly from the GenBank database.

\section{Phylogenetic analysis}

The position of the Niphargus tatrensis species complex within the phylogenetic tree of Niphargidae and its monophyly were inferred by comparison with 222 other Niphargidae species (belonging to Niphargus and closely related genera), using as root three species of the family Pseudoniphargidae, which was suggested to be its sister group in a previous study 


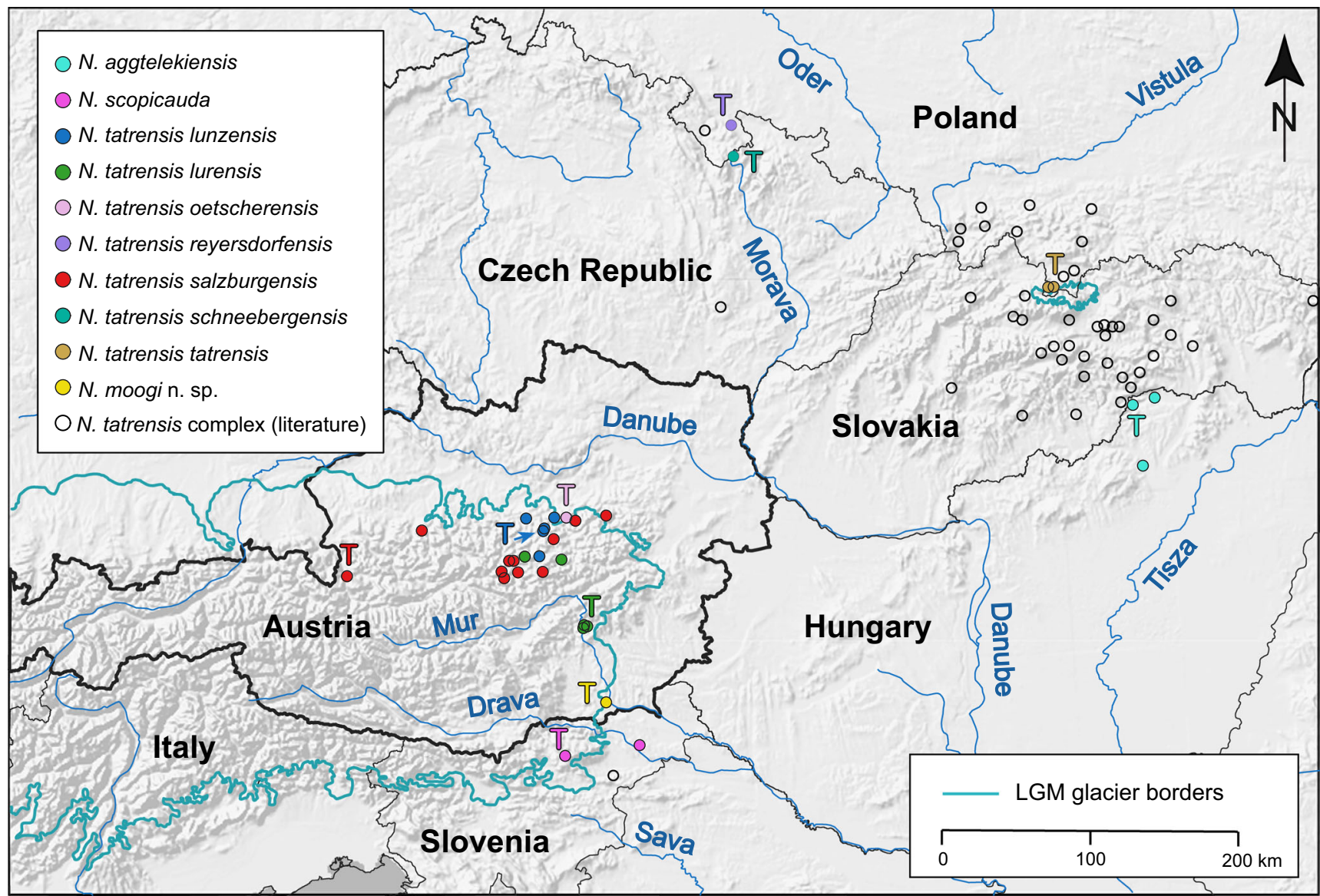

Fig. 1 Distribution of the sampling sites of the Niphargus tatrensis species complex used in the phylogenetic and species delimitation analyses. Names refer to morphospecies identification; T, type locality,
Ice borders at the Last Glacial Maximum (LGM) based on Seguinot et al. (2018) for the Alps and Klapyta and Zasadni (2018) for the Western Carpathians (Tatra Mountains)
(Jurado-Rivera et al. 2017). For this phylogenetic analysis, we assembled a molecular dataset of $22528 \mathrm{~S}$ rRNA gene sequences downloaded from GenBank, supplemented by 17 new sequences of putative members of the species complex (morphospecies names and GenBank accession codes of the 242 sequences used in the analysis are listed in the Electronic supplementary material). All sequences were aligned using the E-INS-i algorithm implemented in MAFFT 7 (Katoh and Standley 2013) and the optimal substitution model (GRT + G $+\mathrm{I}$ ) was selected using ModelFinder (Kalyaanamoorthy et al. 2017) according to the Bayesian Information Criterion (Schwarz 1978). Phylogenetic relationships were reconstructed using maximum likelihood and 1000 ultrafast bootstrap replicates in IQ-TREE 1.6.12 (Nguyen et al. 2015).

The detailed phylogenetic structure of the Niphargus tatrensis species complex and its putative relatives was inferred assembling a molecular dataset that included the fragments of $28 \mathrm{~S}$ rRNA and COI genes. All sequences were aligned using the E-INS-i algorithm in MAFFT v. 7.427 (Katoh and Standley 2013) and concatenated using Fabox 1.5 (Villesen 2007, available at http:/users-birc.au.dk/palle/php/fabox/index.php). The best-fit substitution model for $28 \mathrm{~S}$ and for each COI codon position were selected using ModelFinder (Kalyaanamoorthy et al. 2017) according to the Bayesian Information Criterion (Schwarz 1978). The best-fit models (codes follow the IQTREE manual) were $\mathrm{K} 2 \mathrm{P}+\mathrm{I}$ for $28 \mathrm{~S}$, TNe $+\mathrm{G} 4$ for the first COI codon position, $\mathrm{F} 81+\mathrm{F}+\mathrm{I}$ for the second COI codon position and $\mathrm{F} 81+\mathrm{I}$ for the third COI codon position. Phylogenetic relationships were reconstructed using two methods: (i) maximum likelihood with partition-specific setting and ultrafast bootstrapping (Hoang et al. 2018), using 1000 ultrafast bootstrap replicates in IQ-TREE 1. 6.12 (Nguyen et al. 2015); (ii) Bayesian inference with partition-specific settings in MrBayes 3.2.7 (Ronquist et al. 2012), in two independent runs of four Markov chain Monte Carlo (MCMC) runs with 100,000,000 generations each, sampled every 1000 generations. After reaching stationarity, the first $25 \%$ of the trees were discarded as burn-in and the remaining trees were used to calculate a $50 \%$ majority rule consensus tree. 


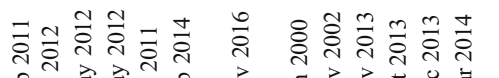

(2)

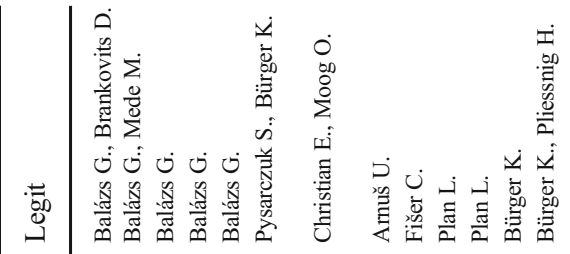

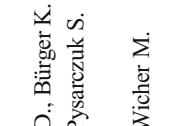

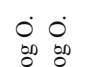

i $\sum \sum \sum_{i}$

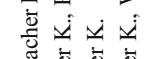

战

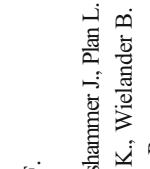

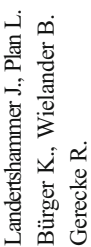

$\ddot{2} \approx \alpha$

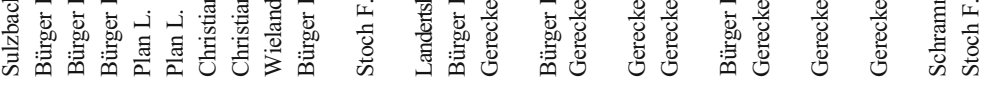

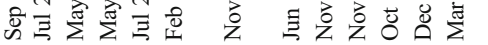

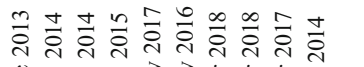

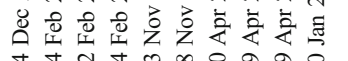

离

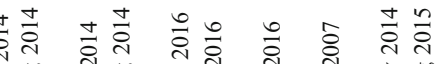
을

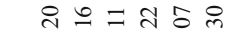

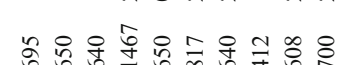

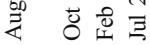

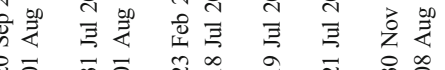

$\varangle$

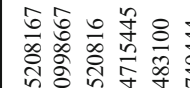

苛

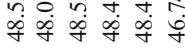

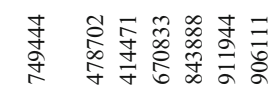

西

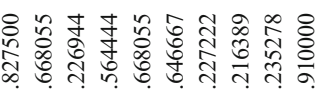

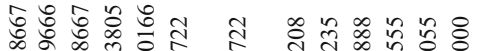

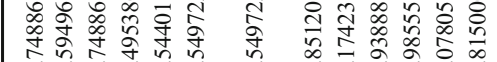

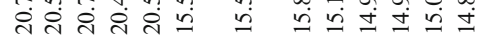

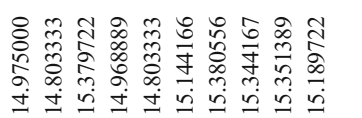

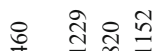

용

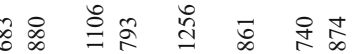

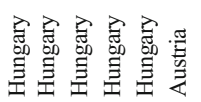

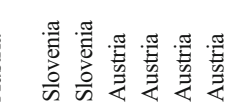

IIIIIII

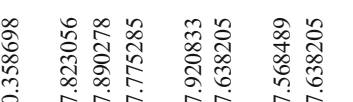

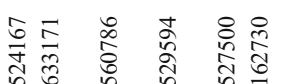

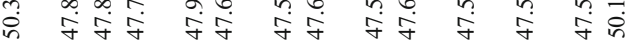

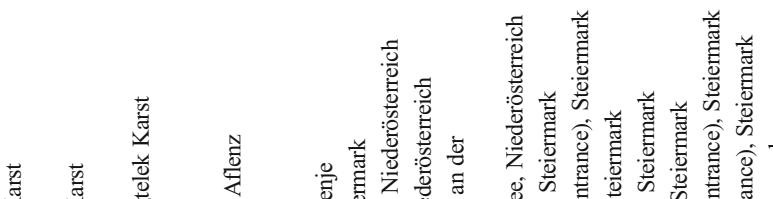

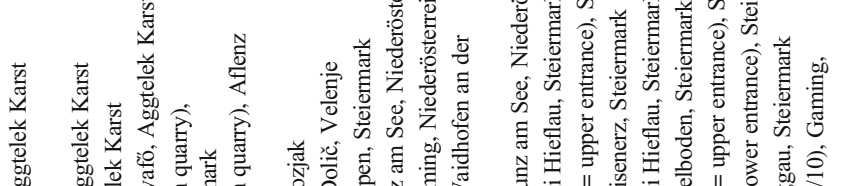

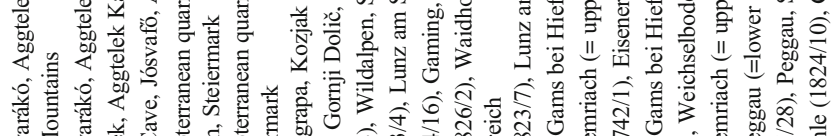

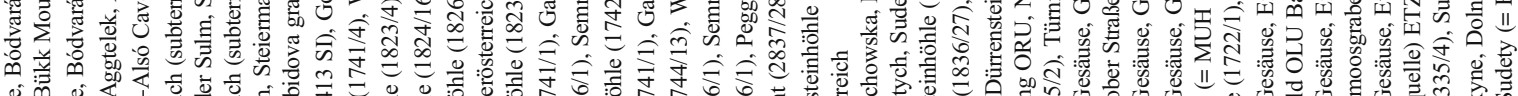

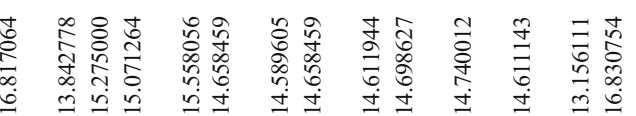

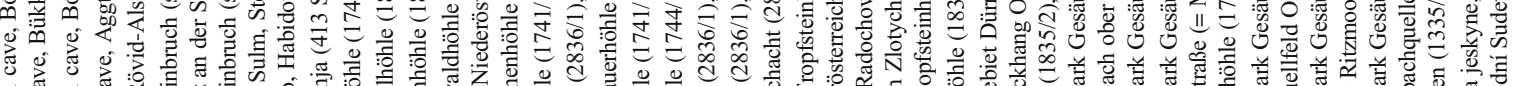

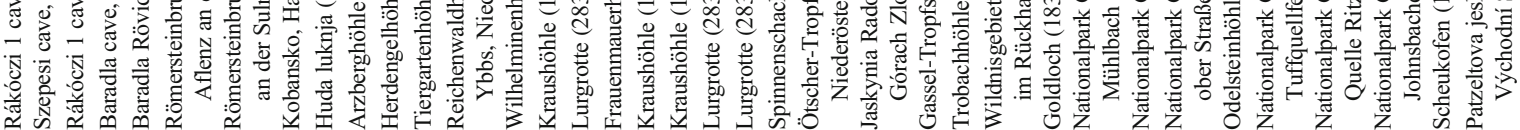

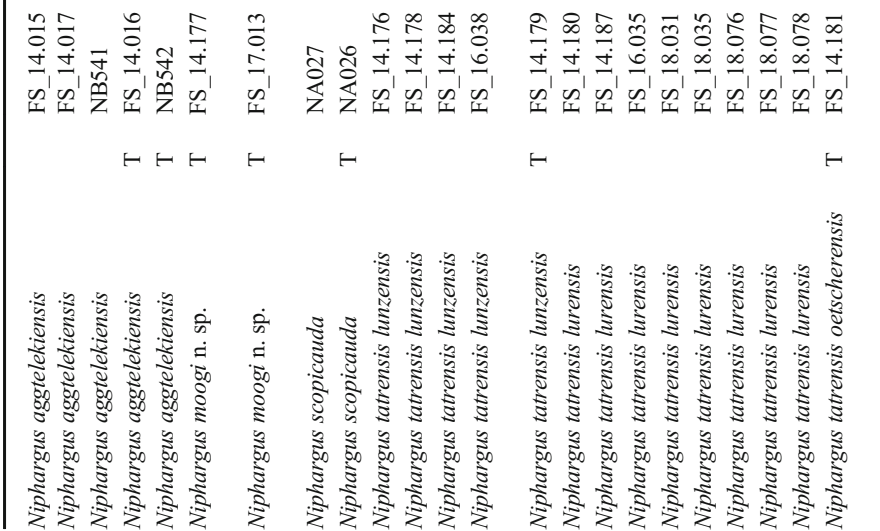

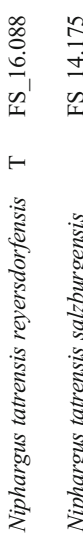

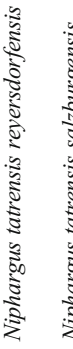

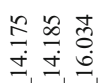

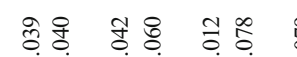

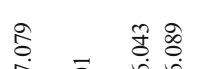

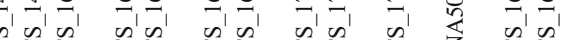
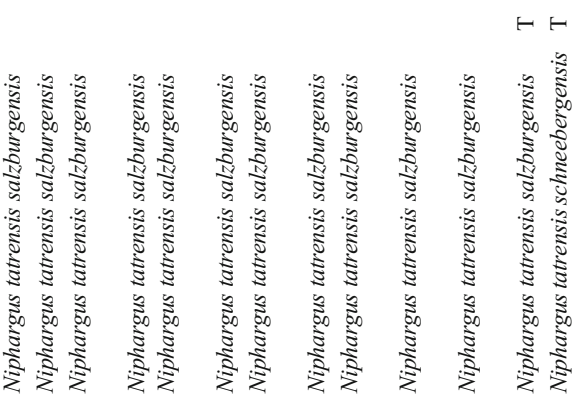


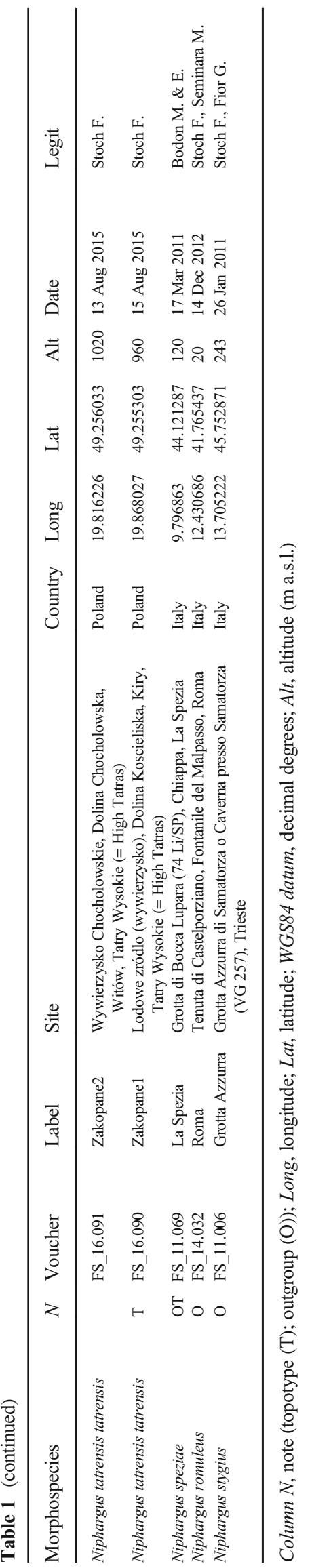

Molecular species delimitation

Putative species were inferred using COI and ITS sequences because these markers have proved suitable in Niphargus taxonomy (Flot et al. 2010a). All three main types of molecular species delimitation approaches were used: distance-, treeand allele sharing-based (Flot 2015).

For COI and ITS sequences, we applied a distance-based delimitation method, i.e. Automatic Barcode Gap Discovery (ABGD; Puillandre et al. 2012) and three tree-based delimitation methods, i.e. the single-threshold Generalised Mixed Yule-Coalescent model (GMYC; Pons et al. 2006) and two Poisson Tree Processes (the Bayesian version bPTP of Zhang et al. 2013 and the multi-rate version mPTP of Kapli et al. 2016).

ABGD was run using the web server (https://bioinfo.mnhn. fr/abi/public/abgd/) with default parameters (Kimura twoparameter substitution model, prior for maximum value of intraspecific divergence between 0.001 and $0.1,10$ recursive steps and a gap width of 1.5).

GMYC requires a fully resolved, ultrametric tree. The tree was produced using Bayesian Evolutionary Analysis Sampling Trees (BEAST) 2.6.1 (Bouckaert et al. 2019), following the best-fit model of evolution proposed by bModelTest (Bouckaert and Drummond 2017). A Yule speciation tree prior was used for the analysis and a lognormal relaxed clock was applied (see below for further details). Four independent runs of $10,000,000$ generations sampled every 1000 steps were performed and combined using LogCombiner 2.6.1. The stationarity of each single run was checked in Tracer 1.7 (Rambaut et al. 2018). The first $10 \%$ of the trees were discarded as burn-in and the remaining samples from the posterior distribution were summarised using TreeAnnotator in the maximum clade credibility tree. The ultrametric tree generated by BEAST was imported in the package splits 1.0-19 (Ezard et al. 2013) in R 3.5.2 (R Core Team, 2019).

PTP was performed, after removing duplicates, using the ML phylogenetic tree obtained using IQ-TREE 1.6.11 as described above. BPTP analysis was run on the species delimitation server http://species.h-its.org/ (MCMC runs of 100,000 generations, sampled every 100 iterations, with $10 \%$ of burn in); mPTP was run on the server https://mptp.h-its.org/\#/tree.

Median-joining haplotype networks (haplonets) of Austrian species for both COI and ITS were produced using the HaplowebMaker Web server (https://eeg-ebe.github.io/ HaplowebMaker/; Spöri and Flot 2020). In the case of ITS, the haplonet was turned into a haploweb by adding connections between haplotypes found co-occuring in heterozyous individuals, allowing to delineate FFRs (fields for recombination sensu Doyle 1995) corresponding to putative species following the criterion of mutual allelic exclusivity (Flot et al. 2010b), which is an allele sharing-based approach to species delimitation. 


\section{Time-calibrated phylogeny and reconstruction of the ancestral states}

A time-calibrated phylogeny based on $28 \mathrm{~S}$ and $\mathrm{COI}$ markers was reconstructed in BEAST 2.6.1 package. Substitution models were unlinked for all partitions (28S and each COI codon), while clock models were linked for COI only, i.e. the same clock model was applied to all the three COI partitions and another one to the 28S partition. Based on marginal likelihood (Path Sampler extension: Baele et al. 2016), a Yule speciation tree prior was used for the analyses. In order to account for lineage-specific rate heterogeneity, a lognormal relaxed clock (Drummond et al. 2006a, b) was used. The coefficient of variation (CV) reported in Tracer 1.7 employing the relaxed clock was higher than 0.1 , suggesting that a relaxed clock fits better the dataset than a strict clock (Drummond and Bouckaert 2015). No fossil is known in the Niphargus tatrensis complex; for this reason, we used the calibrated phylogeny of the genus Niphargus assembled in a previous paper (Delić et al. 2020), where two fossilised Niphargus from Baltic amber of presumed age 35-50 Ma were used as a calibration point. The separation of the Niphargus tatrensis complex from the rest of the genus Niphargus was calculated around $34 \mathrm{Ma}$ (95\% confidence interval between 28 and $42 \mathrm{Ma}$ ), while the beginning of the speciation process within the species complex began around $9 \mathrm{Ma}(95 \%$ confidence interval between 8 and $10 \mathrm{Ma})$. For this reason, a single calibration point (the root of the Niphargus tatrensis species complex) was set to a lognormal distribution with a mean value of $9 \mathrm{Ma}$ and the confidence interval reported above. Three MCMC runs of 20 million iterations were sampled every 2000 iterations, using the best-fit substitution models determined by bModeltest; the three runs were combined using LogCombiner 2.6.1. Convergence (stationarity) in numerical parameters was checked in Tracer 1.7 and the first $10 \%$ of the trees were discarded as burn-in. The Maximum Clade Credibility tree (MCCT) was summarised using TreeAnnotator 2.6.0.

The MCCT obtained from BEAST 2.6.1 was used for palaeobiogeographic reconstruction, inferring the geographic location of ancestors (nodes) using RASP (Reconstruct Ancestral State in Phylogenies) version 4.2 (Yu et al. 2015). Each individual in the time-calibrated tree was scored for the area character state according to the location where the putative species was recovered: Slovenia, North Hungarian Mountains, Tatra Mountains and Sudetes, Southern Austria (Römerstein area), Central Styrian Karst (Lurgrotte area) and Northern Calcareous Alps. Locality inferences on the phylogenetic frameworks were obtained in RASP by applying to the MCCT tree the Bayesian Binary MCMC (BBM) analysis ( $\mathrm{Yu}$ et al. 2015). The BBM method suggests possible ancestral ranges at each node and calculates probabilities of each ancestral range according to tip scores and branch lengths. The
BBM analyses performed ten MCMC runs of 50,000 cycles each, sampling every 100 trees. Chain temperature was set at 0.1 . State frequencies were estimated from the data and among-site rate variation was set using the gamma parameter. The first $20 \%$ of the trees were discarded as burn-in and the remaining trees were used to infer ancestral range distribution at nodes.

BEAST 2.6.1 was used for a more detailed analysis to infer ancestral reconstruction and discrete phylogeography (Bouckaert and Xie 2016) of the Austrian clade. Only the COI marker was used in this analysis, because the $28 \mathrm{~S}$ marker was not informative at intra-specific level and the ITS marker was less variable than COI. Individuals with identical haplotypes were retained due to the different locations of their sampling sites. The protocol reported by Bouckaert and Xie (2016) was followed; three MCMC runs of 10 million iterations were sampled every 1000 iterations, using the best-fit substitution models previously determined by bModeltest; the three runs were combined using LogCombiner 2.6.1. Convergence in numerical parameters was checked in Tracer 1.7 and the first $10 \%$ of the trees were discarded as burn-in. The MCCT of the locations tree was summarised using TreeAnnotator 2.6.0. Species range dynamics were displayed by mapping MCCT branches. Due to the poorly informative chronogram for recent events, relative time units were used (time expressed as a percentage of the age of the oldest ancestor as estimated by the time-calibrated tree).

\section{Results}

\section{Species identification and nomenclatorial analysis}

Revisiting the literature and species catalogues published before 1985, we found that Schellenberg's $(1935,1937,1938)$ forms were explicitly listed as 'subspecies' in the important catalogue of Freshwater Amphipoda of the World by Barnard and Barnard (1983). Following the key provided by Lingafelter and Nearns (2013), the described forms of Niphargus tatrensis therefore fall in their point $6 \mathrm{~b}$, i.e. names adopted as valid names of a species or subspecies before 1985, and thus deserve subspecific status. For this reason, following the provisions of article 45.6.4 of the International Code of Zoological Nomenclature (ICZN), we established that the abovementioned names are available, and all the Schellenberg's $(1935,1937,1938)$ forms are to be treated as subspecies and should be added to the on-line catalogues.

Species identification was easy for the Eastern European species, where topotypic material was examined. Regarding the Austrian clade, Schellenberg's (1935) key (points 71-81 deal with the described forms of $N$. tatrensis) allowed to attribute all the Austrian specimens to one of the described forms, 
although differences were not always sharp. The key was based on three characters only: number of spines on telson, number of spines on pereopod dactylopodites and mouthpart setation. $N$. tatrensis lunzensis, $N$. tatrensis salzburgensis and $N$. tatrensis lurensis from type locality were easily distinguished, althought some specimens with varying characters (especially dactylopodite spines) were assigned to a certain form or another based on the prevailing morphotype in the population. The mouthpart differences distinguishing $N$. tatrensis oetscherensis from $N$. tatrensis lurensis were unreliable, so that only the topotypic material was attributed to $N$. tatrensis oetscherensis, while the other populations were attributed to $N$. tatrensis lurensis.

\section{Phylogenetic analysis and molecular species delimitation}

Phylogenetic analyses confirmed the monophyly of the $N$. tatrensis species complex as defined by Fišer et al. (2010) with $100 \%$ bootstrap support (Fig. S2 in the Electronic supplementary material).

In the detailed phylogenetic analysis reported in Fig. 2, both maximum likelihood and Bayesian inference resulted in similar trees; therefore, ultrafast bootstrap support and Bayesian posterior probabilities are reported on the ML tree. Within the species complex there were three strongly supported clades (Fig. 2): (i) the Niphargus tatrensis s. str. clade, including the nominotypical subspecies, $N$. tatrensis reyersdorfensis from southern Poland and $N$. tatrensis schneebergensis from Czech Republic; (ii) N. aggtelekiensis, including only the populations from its terra typica, the Aggtelek Karst in Hungary; (iii) the Austrian clade (posterior probability $=1$, bootstrap $=98 \%$ ). Within the Austrian clade, some specimens identified as $N$. tatrensis lurensis on a morphological basis turned out to belong to $N$. tatrensis salzburgensis.

Species delimitation methods were first applied to the COI dataset, i.e. to the whole $N$. tatrensis species complex excluding $N$. scopicauda, for which no reliable COI sequence was available. In fact, the sequence present in GenBank must refer to an isopod crustacean (see Table S2), and unfortunately no more specimens have been collected and sequenced so far from Slovenia: Zakšek and Borko, personal communication.

The results are illustrated in Fig. 3 (putative species number in brackets): ABGD (10), mPTP (7), bPTP (11) and GMYC (11). The morphospecies delimitation based on the cladistic analysis by Fišer et al. (2010) is reported for comparison. The differences in the number of putative species resulting from the application of the four above-mentioned methods indicated different levels of splitting rather than alternative haplotype segregations. Restricting species delimitation methods to the focal area of Austria, all species delimitation methods applied to the COI dataset converged to four putative species ( $N$. tatrensis salzburgensis $+N$. tatrensis oetscherensis, $N$. lunzensis, $N$. lurensis and $N$. moogi n. sp.), clearly identifiable observing the haplotype network (Fig. 4). On the other hand, the same methods applied to the ITS dataset indicated the presence of three species only; a further analysis using haploweb concurred in distinguishing the same three putative species as FFRs (fields for recombination) as well (Fig. 4), suggesting that $N$. tatrensis salzburgensis (including $N$. tatrensis oetscherensis) and $N$. tatrensis lunzensis belong to the same gene pool.

\section{Time-calibrated phylogeny and biogeographical inference}

The first split within the Niphargus tatrensis species complex (Fig. 5) was dated to the Late Miocene, about $9 \mathrm{Ma}$ (confidence interval $8-10 \mathrm{Ma}$ ), with the separation of the $N$. aggtelekiensis $+N$. scopicauda subclade, while the Austrian clade splitted from the Eastern clade of $N$. tatrensis about $8 \mathrm{Ma}$ (confidence interval 6.8-9.3 Ma). The node support for the common ancestor of the Eastern clade of $N$. tatrensis and the Austrian clade was quite low (0.68), so it has to be treated with caution, suggesting that the polytomy giving rise to three clades in the Miocene (Fig. 5) is not resolved by the markers in hand. The split of the species from Römerstein from the rest of the Austrian clade took place about 5.8 Ma (confidence interval, 4.5-7.1 Ma), while the separation of $N$. tatrensis lurensis was dated about $4.4 \mathrm{Ma}$ (confidence interval, 3.3-5.6 Ma). Roughly during the same time span $N$. scopicauda splitted from N. aggtelekiensis. The $N$. tatrensis salzburgensis and $N$. tatrensis lunzensis clades separated in the Early Pleistocene before the beginning of Quaternary glaciations, around 2.3 Ma (confidence interval, 1.5-3.1 Ma). The time of the most recent series of splits within the Austrian clade coincided with Pleistocene glaciations.

The BBM model of ancestral range reconstruction indicated that the Austrian clade originated in Eastern Europe (Fig. 5). Due to the uncertainty of the split between $N$. tatrensis and $N$. aggtelekiensis, it is not safe to say that the ancestral area was in the Tatra Mountains rather than in North Hungarian Mountains. In any case, an Eastern origin is strongly supported.

These splits are recapitulated in a paleogeographic scenario illustrating the origin and dispersal of this species complex, followed by vicariance events (Fig. 6a-d). The putative area of origin was occupied around $15 \mathrm{Ma}$ by an arm of the Paratethys ocean (Fig. 6a), with a complex fragmentation of landmasses. The first split within the $N$. tatrensis complex happened after the regression of the Paratethys around 7.5$10 \mathrm{Ma}$, when a connection between the Tatras and the North Hungarian Mountains, and between the Western Carpathians 


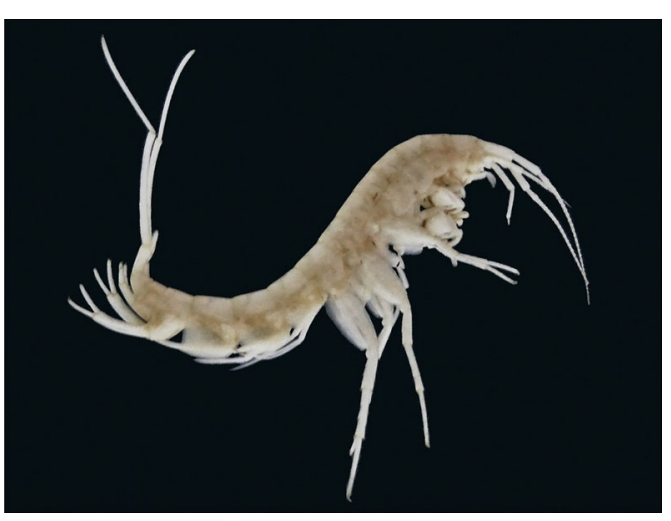

FS.16_034 Niphargus tatrensis salzburgensis Dürrenstein FS.16_042 Niphargus tatrensis salzburgensis Gesäuse4 FS.16_035 Niphargus tatrensis salzburgensis Frauenmauer FS.16_043 Niphargus tatrensis salzburgensis Scheukofen FS.16_040 Niphargus tatrensis salzburgensis Gesäuse2 FS.17_078 Niphargus tatrensis salzburgensis Gesäuse5 FS.17_079 Niphargus tatrensis salzburgensis Geäuse6 FS.14_175 Niphargus tatrensis salzburgensis Gassel FS.14_181 Niphargus tatrensis oetscherensis Ötscher FS.16_034 Niphargus tatrensis salzburgensis Odelstein FS.16_060 Niphargus tatrensis salzburgensis Gesäuse2 NA501 Niphargus tatrensis salzburgensis Gesäuse ETZB FS.14_185 Niphargus tatrensis salzburgensis Trobach FS.14_180 Niphargus tatrensis lurensis Kraus FS.18_031 Niphargus tatrensis lurensis Kraus FS.18_035 Niphargus tatrensis lurensis Kraus Weichsel

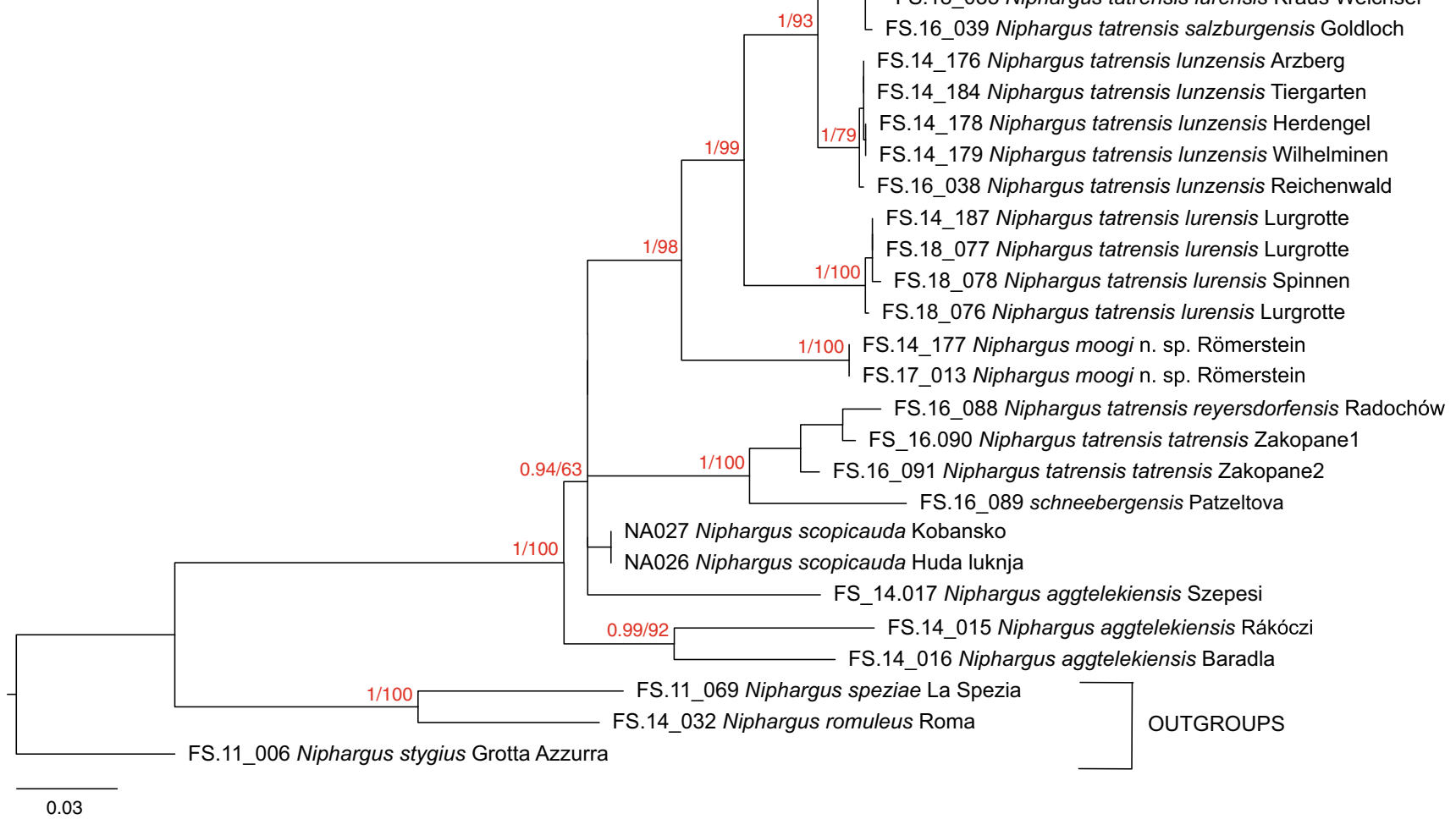

Fig. 2 Maximum-likelihood molecular phylogeny (IQ-TREE) of the Niphargus tatrensis complex, built using 28S rRNA and COI concatenated sequences. The node support values shown are Bayesian posterior

and the Alps, allowed dispersal followed by vicariance events (Fig. 6b). The situation during the Pliocene did not show major changes of the general scenario, with the reduction of the Pannonian Lake and a further dispersal from the North Hungarian Mountains to the Drava Basin giving origin to $N$. scopicauda (Fig. 6c). The Pleistocene history allowed an expansion of the range of the Austrian clade in the Alpine area (Fig. 6d); the first splits took place before the beginning of the Quaternary glaciations.

Considering that the model based on concatenated nuclear and mtDNA markers was not able to infer the most recent historical biogeography of the Austrian clade, an ancestral reconstruction and discrete probabilities and maximum-likelihood bootstrap frequencies. Upper left, Niphargus moogi n. sp. (male, $19 \mathrm{~mm}$ ), the new species discovered in southern Austria (photo: E. Christian)

phylogeography of this clade was inferred by BEAST on the COI marker alone. The distribution of the root locations showed that the 95\% HPD consisted of all locations. There was not a strong indication of a single root as the origin of the clade, since all the localities had similar probabilities (around 4-6\%). This was indicative of a quite recent origin of the different haplotypes modelled by the Pleistocenic glaciations, illustrated in Fig. 6e. From the biogeographic inference model, both dispersal from the northern refugial areas to the central area of the current distribution range and dispersal towards East and West (Fig. 6e) can be hypothesised. 


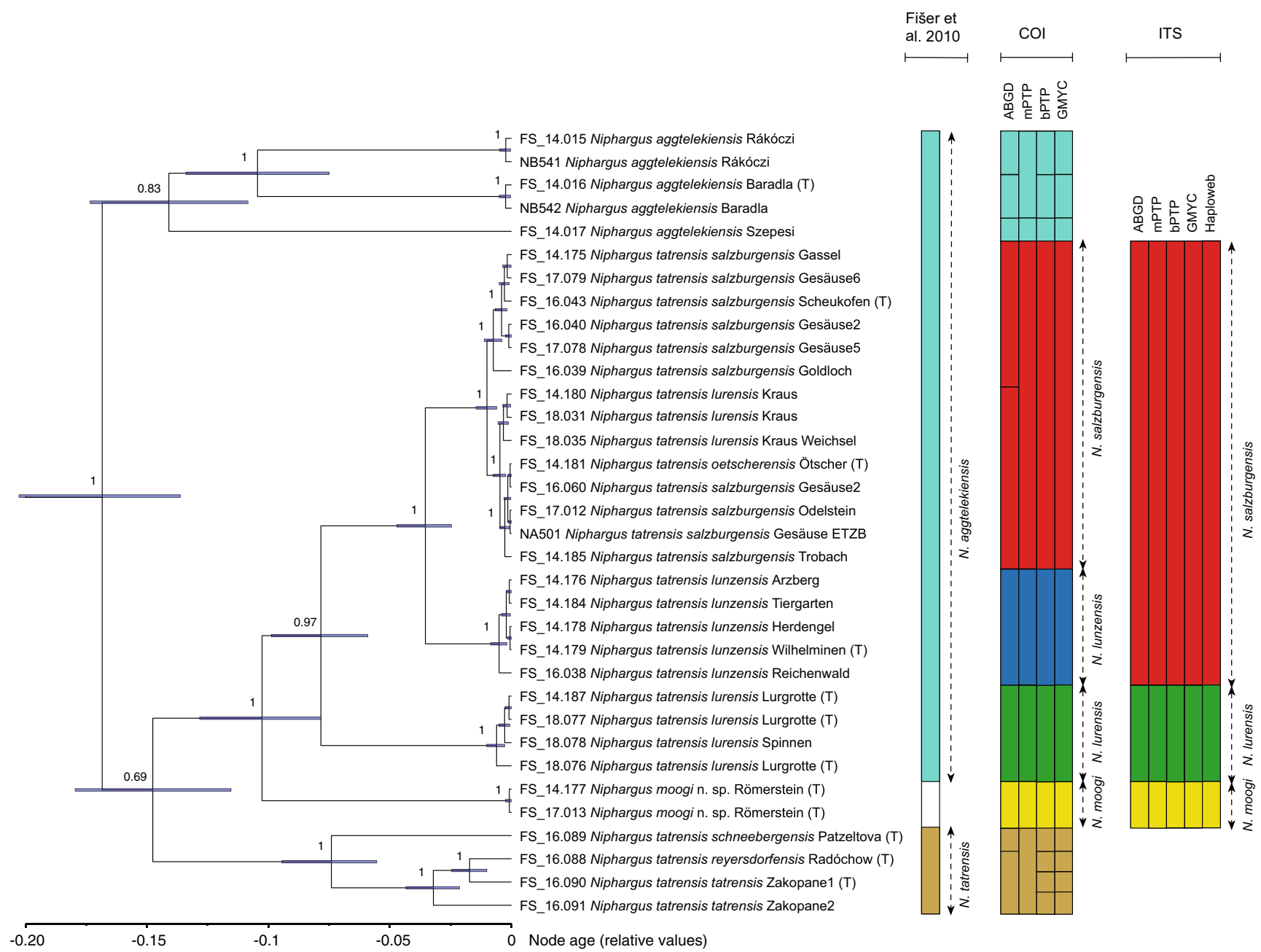

Fig. 3 Results of the species delimitation methods compared with the maximum clade credibility tree of the Niphargus tatrensis complex, derived from BEAST analysis of COI sequences. Both the posterior probabilities of each node and the $95 \%$ confidence interval on its relative age (shown as a blue bar) are reported. Morphospecies delimitation is derived by the cladistic analysis conducted by Fišer et al.

\section{Discussion}

\section{Phylogenetic analysis and species delimitation}

Phylogenetic analysis confirmed that all members of the Niphargus tatrensis species complex form a monophyletic group. Within this clade, the analysis clearly showed that: (i) $N$. aggtelekiensis from North Hungarian Mountains is a separate clade; (ii) $N$. tatrensis with its two subspecies $N$. tatrensis schneebergensis and $N$. tatrensis reyersdorfensis form a monophyletic group, and $N$. tatrensis schneebergensis from Sudetes is close to the topotypical $N$. tatrensis populations from the Tatra Mountains, Poland; and (iii) the Austrian populations form a clade neither included in $N$. tatrensis (as originally supposed by Schellenberg 1935,1937 ) nor in N. aggtelekiensis (as hypothesised by Fišer et al. 2010).
(2010). Molecular species delimitation methods applied to COI are Automatic Barcode Gap Discovery (ABGD), Bayesian Poisson-Tree Processes (bPTP), multi-rate Poisson-Tree Processes (mPTP) and the Generalised Mixed Yule Coalescent model (GMYC). Molecular species delimitation methods using ITS (the previously mentioned four methods as well as haploweb) were applied to the Austrian clade only

Morphological identification using Schellenberg's (1935) key has proven unreliable, and some specimens of $N$. tatrensis salzburgensis were wrongly attributed to $N$. tatrensis lurensis. We were not able to point out constant differential morphological characters especially for the Austrian species, confirming the problems highlighted by Fišer et al. (2010).

The different molecular species delimitation methods based on the mitochondrial COI marker gave very different results when applied to the whole $N$. tatrensis species complex, with putative species number ranging from 8 to 11 . The most conservative method was the recently developed $\mathrm{mPTP}$, where $N$. tatrensis was considered a single species and $N$. aggtelekiensis a complex of two different species. More material will be needed to establish whether $N$. tatrensis and $N$. aggtelekiensis are two species or two complexes of cryptic species. At least the latter seems to be a species aggregate, the 
Fig. 4 Median-joining haplotype networks for COI and ITS markers produced using the HaplowebMaker web server for the Austrian specimens. The ITS network was turned into a haploweb by adding curves connecting the two haplotypes of heterozygous specimens. The haplotypes are coloured according to the COI haplogroup to which they belong

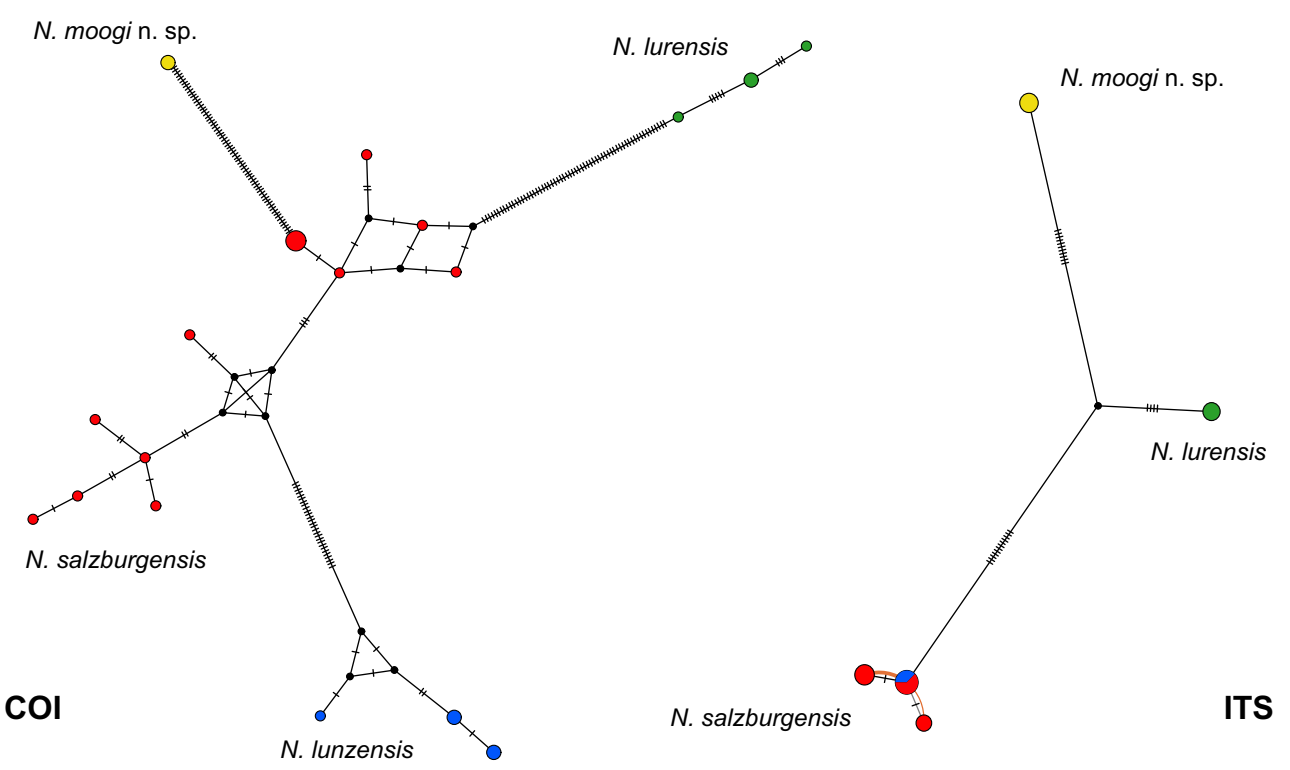

N. aggtelekiensis population from Szepesi cave (Bükk Mountains, Hungary) belonging to a putative, yet undescribed cryptic species.

Focusing our analyses on the Austrian clade, all species delimitation methods applied to the $658-\mathrm{bp}$ mitochondrial COI gene fragment clearly identified four primary species hypotheses for this marker: (1) N. salzburgensis (including $N$. tatrensis salzburgensis together with $N$. tatrensis oetscherensis and part of the material identified as $N$. tatrensis lurensis); (2) N. lunzensis (comprising only specimens attributed morphologically to $N$. tatrensis lunzensis); (3) N. lurensis (from the type locality of Niphargus t. lurensis and a nearby cave in the Central Styrian Karst); (4) N. moogi n. sp. from Römerstein quarry. While $N$. lurensis and $N$. moogi n. sp. inhabit isolated areas, the other two groups share the same range in the eastern part of the Northern Calcareous Alps.

By contrast, all species delimitation methods applied to the nuclear ITS delimited only three primary species hypotheses, with the haploweb showing that the ITS sequence type of $N$. lunzensis is also shared with $N$. salzburgensis.

We suggest two possible explanations of the different number of putative species delineated by COI and ITS markers in the Niphargus tatrensis complex from Austria. Firstly, the discrepancy could be due to sex-biased dispersal (Eberle et al. 2019). Female philopatry may strongly increase reciprocal monophyly of mitochondrial markers, causing oversplitting in species delimitation using COI. In such situation, a strong correlation of $\mathrm{COI}$ and recent paleogeographical vicissitudes, as seen in our study, is expected, even though ITS suggests panmixis. Unfortunately, no data on sex-biased dispersal exist in Niphargus or other groundwater taxa, although it is known in marine amphipods (i.e. tube-building species of the genus Corophium: Munguia 2015). This hypothesis deserves to be tested in detail in future research. A further plausible explanation of COI-based oversplitting may be found in a recent paper by Hijonosa et al. (2019). These authors showed that highly divergent COI lineages coexist in a widespread European butterfly, but none of the hundreds of nuclear markers analysed was associated with mitochondrial lineages, ruling out the presence of cryptic species. These results, as remarked by Després (2019), hint at a complex demographic history of lineage divergence/fusion during the Pleistocene climatic fluctuations. A similar situation was suggested to explain the discordance in variation of ITS and COI markers in the amphipod Crangonyx islandicus, inhabiting Icelandic groundwaters, which survived in subglacial refugia during the Pleistocene. Although Kornobis and Pálsson (2011) stated that the lower variation of ITS region compared with COI may hide the presence of cryptic species, Eme et al. (2017a), using ddRADSeq analysis, showed that a large majority of the nuclear markers supported the ITS scenario.

Based on this evidence and relying on the fact that most of the recent splits in the Austrian clade of the Niphargus tatrensis complex took place during Pleistocene, we select as secondary species hypotheses the species suggested by the ITS region. Further investigation using, e.g. RADseq or low-coverage whole-genome sequencing will be required to test our hypothesis that $N$. salzburgensis and $N$. lunzensis are indeed conspecific.

The presence of two highly divergent lineages evidenced by COI gene fragment leaves open the possibility of assigning them a taxonomic rank of subspecies. A subspecies may be defined as a 'collection of populations occupying a distinct range and diagnosably distinct from other such populations' (Patten 2015 and references therein). In the case of the two lineages above, the distinction of the ranges is weak, the morphological differential diagnosis is very difficult (Fišer et al. 


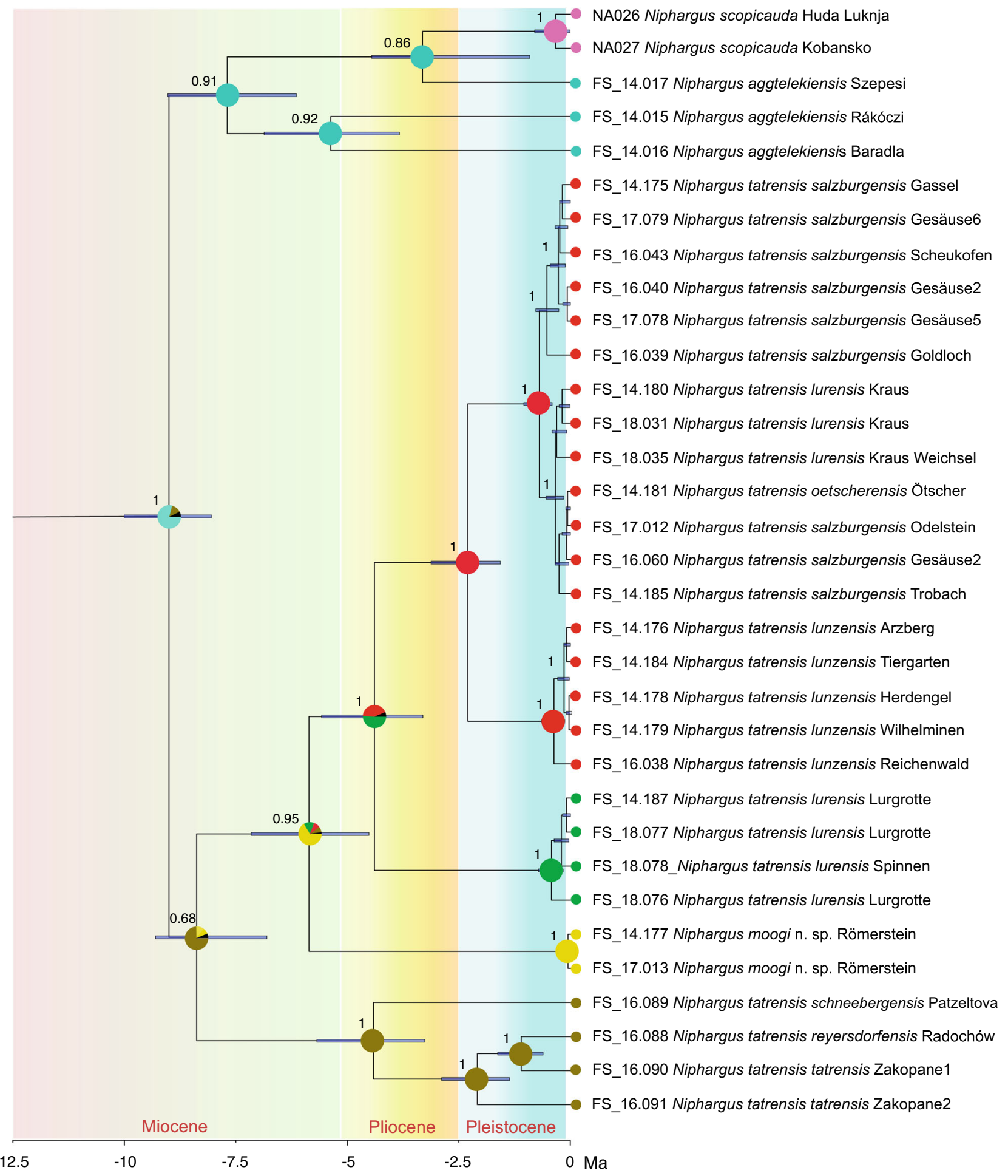

Fig. 5 Time-calibrated maximum clade credibility tree of the Niphargus tatrensis species complex derived from a BEAST analysis of concatenated $28 \mathrm{~S}$ and COI sequences. Both the posterior probabilities of the nodes and the $95 \%$ confidence intervals of their ages are reported. Colours of node dots and wedges of pie charts represent the ancestral area of distribution of each main clade (Slovenia: purple; North

Hungarian Mountains: light blue; Tatra Mountains: light brown; Southern Austria: yellow; Central Styrian Karst: green; Northern Calcareous Alps: red) used in the ancestral range reconstructions estimated using a Bayesian Binary MCMC (BBM) analysis. Pie charts superimposed on nodes indicate the relative probabilities of all possible ancestral ranges (black widges, undetermined) 

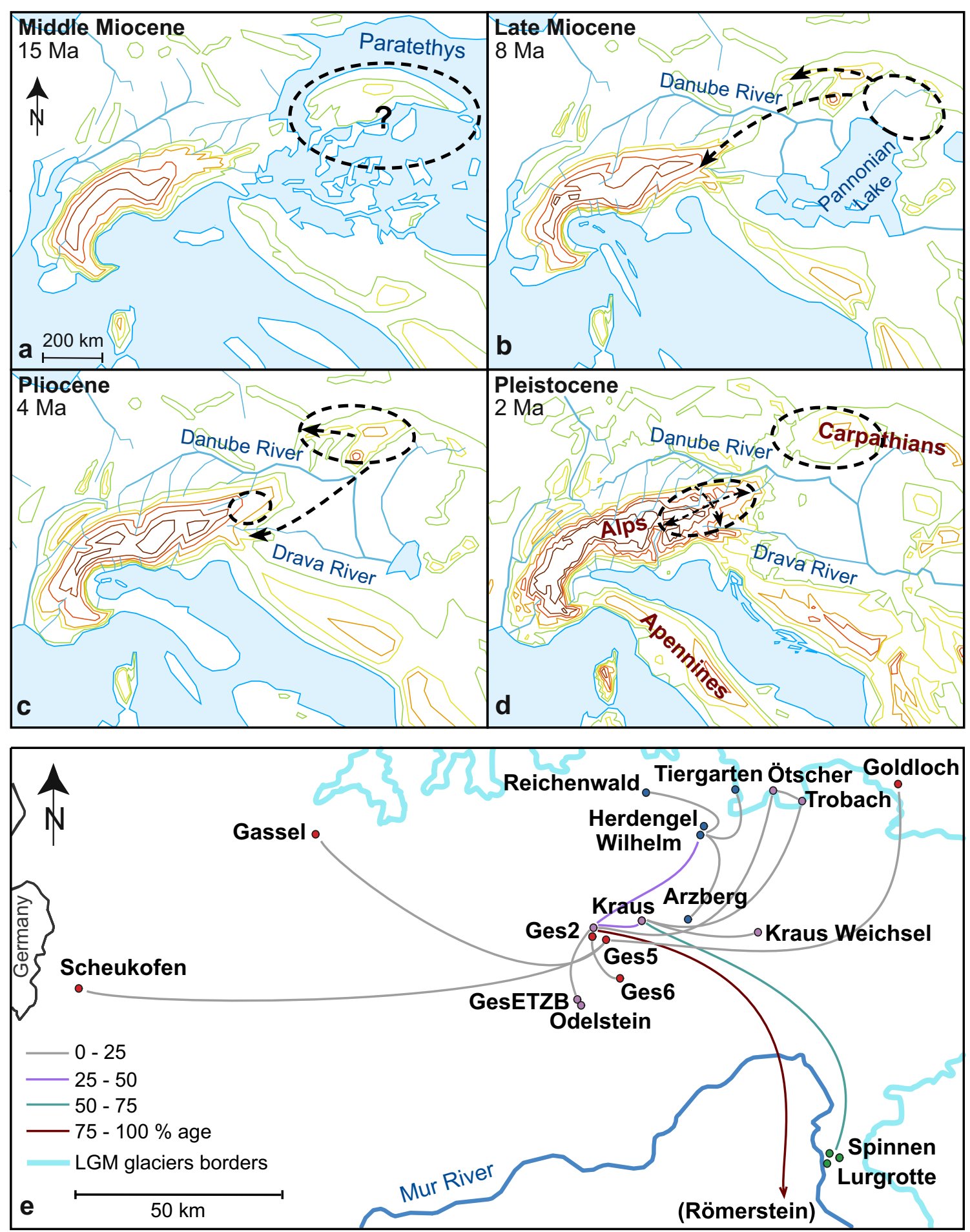

Fig. 6 a-d Biogeographic reconstruction of the Alpine-Carpathian area from Middle Miocene to Pleistocene, according to Winterberg and Willett (2019); black arrows, hypothetical dispersal routes as derived from the Bayesian Binary MCMC analysis (BBM). e Postglacial range dynamics of the Austrian clade inferred from a BEAST analysis of COI sequences;

2010) and genetic differences alone are not enough to justify a subspecies (Mousseau and Sikes 2011; Patten 2015). As a consequence, we refrain from conferring subspecific rank to these lineages in spite of their COI divergence.
Last Glacial Maximum (LGM) ice borders are reported. Maximum clade credibility tree branches are projected on the map, with colours representing the relative age of branches compared with the age of the most recent common ancestor of the Austrian clade

\section{Historical biogeography}

All our results favour the hypothesis that the Austrian clade of the $N$. tatrensis species complex derived from an ancestor that 
settled in Eastern Europe along the mainland shore of the Paratethys Ocean or on one or more of the islands that were, in the Middle Miocene, in the region currently occupied by the eastern clades (Winterberg and Willett 2019). The isolation of the putative ancestor in one of these landmasses may explain the long stasis between the separation of the common ancestor from the other Niphargus species (dated at 28-45 Ma; Delić et al. 2020) and the first known split within the $N$. tatrensis species complex dated around 7.5-10 Ma. This pattern is quite congruent with that of surface water gammarids in the Carpathians (Copilaş-Ciocianu and Petrusek 2017). Therefore, these independent studies strengthen the view that the isolated Carpathian islands promoted lineage divergence during the Miocene.

The Pleistocene history allowed an expansion of the range of the Austrian clade into the Alpine area, and the first split took place before the onset of the first glaciation. The detailed model applied to the Austrian clade suggested a quite recent origin of the different haplotypes and cycles of long-range dispersal followed by subsequent contact during the Pleistocene climate fluctuations. Nearly all the area occupied by the current range of the Austrian clade was buried under an ice cover during the Last Glacial Maximum (LGM) of the Würm glaciation, some 21,000 years ago (Seguinot et al. 2018). The ancestor location in the center of the distribution range (around Gesäuse National Park), suggested by the analysis and in agreement with the assumption that older genetic variants are more centrally located (as hypothesised for Niphargus puteanus Koch, 1836 by Weber et al. 2020), may be misleading in this case. Although re-colonisation from local refugia cannot be ruled out completely, our analysis suggests that the common ancestor of the different haplogroups of the $N$. salzburgensis clade lived in refugial areas along the northern border of the glaciers, and subsequent dispersal took place during interglacial periods, most probably after the LGM. Our analyses suggest both dispersal from the northern refugial areas to the central area of the current distribution range, as well as long dispersal routes towards East and West. The same haplogroup ( $N$. salzburgensis $\mathrm{s} . \mathrm{str}$.) is present in a wide W-E stretch along the Northern Calcareous Alps, spanning $187 \mathrm{~km}$ from Scheukofen near Salzburg to Goldloch near Türnitz in Lower Austria. This is remarkable, as ranges of more than $200 \mathrm{~km}$ are very rarely detected in Niphargus species (Trontelj et al. 2009).

\footnotetext{
Acknowledgements The authors are indebted to all the collectors, scientists and speleologists, who, thanks to their expertise, provided samples from caves and springs in Austria and Hungary. These colleagues are acknowledged by name in Table S1. Authors are particularly grateful to Reinhard Gerecke (Tübingen) for samples collected in Gesäuse National Park springs systems and to Gergely Balázs (Budapest) for providing fresh material from Hungarian caves.
}

Funding This research was funded by the Belgian Fonds de la Recherche Scientifique (FNRS) via research credit J.0272.17 and by the Fédération Wallonie-Bruxelles via an 'Action de Recherche Concertée' (ARC) grant, both to Jean-François Flot.

Data availability All specimens used for descriptions and DNA vouchers are deposited in a public collection; all the sequences are deposited in GenBank; all data and materials will be publicly available.

\section{Compliance with ethical standards}

Conflicts of interest The authors declare that they have no conflict of interest.

Ethics approval No ethic approval required.

Consent to participate Not applicable.

Consent for publication All the authors agree on publishing data; no further approval required.

Code availability Not applicable.

\section{Appendix 1. Taxonomic section}

Based on the results of molecular analysis, we recognise the presence in Austria of three species of the $N$. tatrensis complex, viz. N. salzburgensis Schellenberg 1935 stat. nov., N. lurensis Schellenberg 1935 stat. nov. and N. moogi n. sp.

Niphargus salzburgensis Schellenberg, 1935 stat. nov.

Synonyms. Niphargus tatrensis f. salzburgensis, Niphargus tatrensis f. lunzensis, Niphargus tatrensis f. ötscherensis: Schellenberg 1935, 1937; Niphargus tatrensis (partim): Strouhal \& Vornatscher 1975 (and references cited herein); Niphargus tatrensis otscherensis, Niphargus tatrensis lunzensis, Niphargus tatrensis salzburgensis: Barnard \& Barnard 1983; Niphargus aggtelekiensis (partim): Fišer et al. 2010, Eme et al. 2018; Niphargus aggtelekiensis: Fišer et al. 2012; Niphargus tatrensis: Fritsch 2018.

Type locality. Scheukofen (number 1335/4 of the Austrian cave cadaster), Sulzau bei Werfen, Salzburg.

Distribution. Widely distributed in Austria along the eastern part of the Northern Calcareous Alps.

Diagnosis. See Schellenberg (1937).

Remarks. Considering that the three available names for this species were originally described in the same paper (Schellenberg 1935) and made available in a single paper (Barnard \& Barnard 1983), the precedence of names cannot be determined. Consequently, following ICZN article 24.2 (Determination by the First Reviser) and Recommendation 24A (Action of the First Reviser), we selected $N$. salzburgensis as the name that will best serve stability of nomenclature, considering that the clade to which topotypic specimens belong is the most widely distributed.

Niphargus lurensis Schellenberg, 1935 stat. nov. 
Synonyms. Niphargus tatrensis f. lurensis: Schellenberg 1935, 1937, Vornatscher 1952; Niphargus tatrensis: Strouhal \& Vornatscher 1975 (and references cited herein); Niphargus tatrensis salzburgensis: Barnard \& Barnard 1983; Niphargus aggtelekiensis: Fišer et al. 2010, Christian \& Spötl 2010, Eme et al. 2018.

Type locality. Lurgrotte (2836/1), Semriach, Steiermark.

Distribution. Known only from the type locality and a nearby cave in the Central Styrian Karst.

Diagnosis. See Schellenberg (1937).

Niphargus moogi n. sp.

Zoobank paper: urn:lsid:zoobank.org:pub:560E14BC4CAD-4E04-B392-490B7E8770EE

Zoobank new species act: urn:lsid:zoobank.org:act:8DCB14EA82E0-41BC-BF72-EC2080D50DD2
Etymology. The species is dedicated to the Austrian limnologist and biospeleologist Prof. Dr. Otto Moog.

Material examined. Holotype (male $19 \mathrm{~mm}$ ), Römersteinbruch (subterranean quarry), Aflenz an der Sulm, Steiermark, Austria, 29 Nov 2016, leg. O. Moog and E. Christian. Paratypes, 3 males and 1 female, same locality and collection date. Appendages of holotype and part of female paratype dissected and mounted on microscopic slides in Faure's medium; remaining parts of the body and other paratypes preserved in $75 \%$ EtOH with $10 \%$ glycerine added. Type material deposited in the Natural History Museum in Vienna under the numbers NHMW 26660 (holotype) and NHMW 2666126664 (paratypes).

Description of male holotype. Body length of $21 \mathrm{~mm}$. Head length $10 \%$ of body length; rostrum absent. Pereonites I-VI
Fig. 7 Niphargus moogi n. sp. holotype male. a Antenna I; b accessory flagellum of antenna I; $\mathbf{c}, \mathbf{d}$ articles 30 and 31 of antenna I; e antenna 2; f distal article of antenna $2 ; \mathbf{g}$ right mandible; $\mathbf{h}$ left mandible; i mandibular palp, outer side; $\mathbf{j}$ distal article of mandibular palp, inner side. Scale bars, $0.1 \mathrm{~mm}$

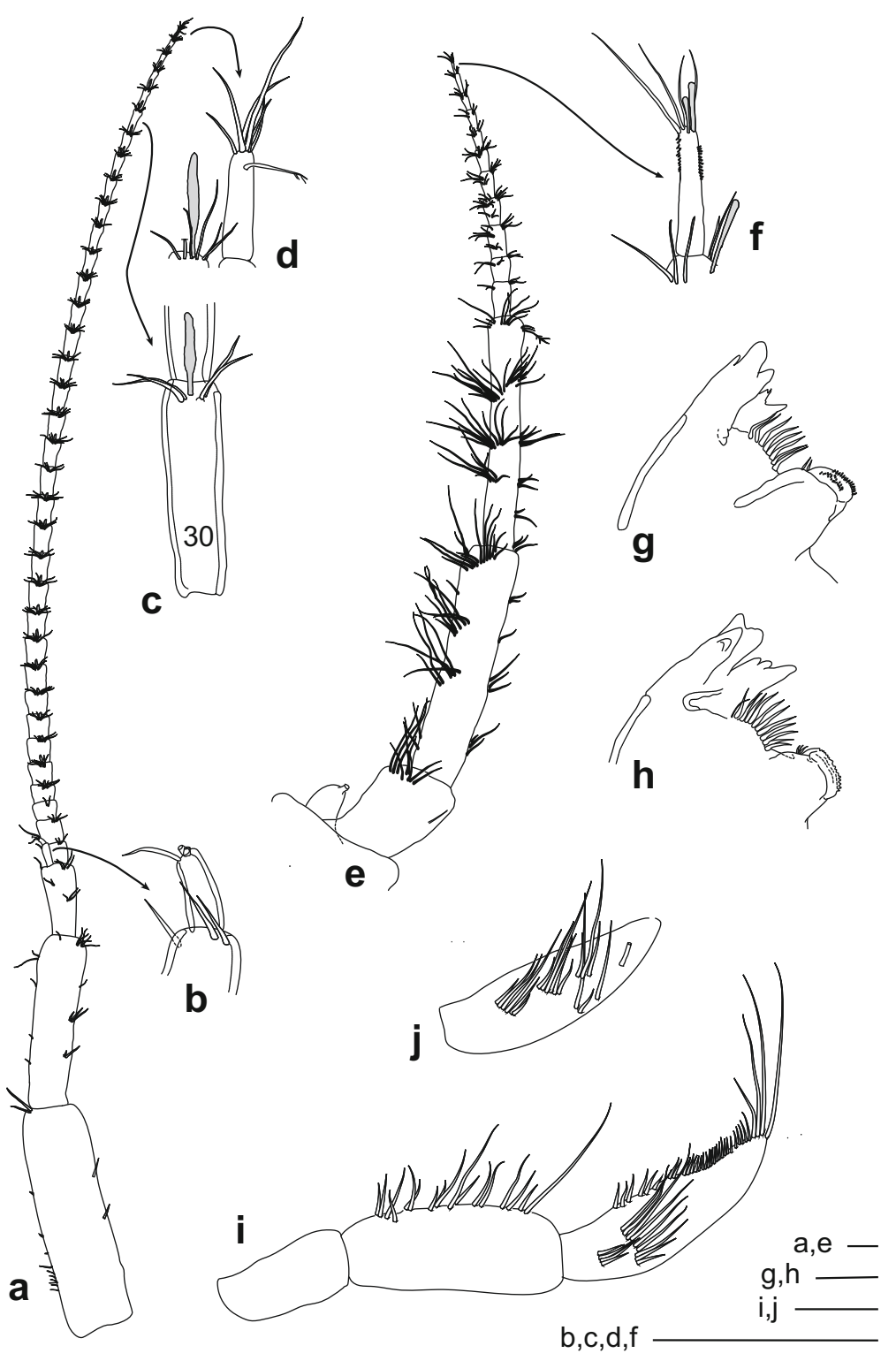


with 2-3, pereionite VII with 4 small dorso-medial sensorial setae. Pleonites I-III with 6-7 small dorsal sensorial setae and 3-4 dorso-posterior, thin and longer setae. Epimeral plate I withot ventral setae, with 1 postero-distal spiniform seta; plate II and III with 3 strong setae along ventral margin and 1 seta close to postero-ventral corner; plate III with posterior and ventral margins slightly convex, posterior ventral corner rounded, not produced. Urosomites II and III with 2 dorsolateral setae. One short spine present near insertion of uropod I.

Antenna I (Fig. 7a). 40-46\% of body length. Flagellum with of 35 articles; each article with 1 aesthetasc (Fig. 7c), its length about one third of article length; aesthetasc accompanied by 4-6 setae. Distal article shorter (Fig. 7d), as long as the aesthetasc of penultimate article, bearing 6 distal and 1 posterodistal setae. Peduncle article triarticulated (Fig. 7a), proportions of articles length 1:2:3 as 1.0:0.75:0.30. Accessory flagellum biarticulated (Fig. 7b); proximal article bearing three distal setae; distal article as long as one third of proximal article, bearing 2 setae.

Antenna II (Fig. 7e) as long as one third of antenna I. Flagellum of antenna II with 11 articles; each article with 58 setae and elongated sensilla; penultimate article bearing an aesthetasc; distal article (Fig. 7f) with dorsal and ventral margins ornamented by a longitudinal row of spinules, bearing 4 distal setae accompanied by 2 aesthetascs of different length. Peduncle with proportions of articles length $3: 4: 5$ as 1.0:2.75:2.70; articles 4 and 5 slender, rows of ventral setae longer than article length; flagellum $50-60 \%$ of peduncle length.

Outer lobe of labium and labrum as in Fig. 8a, b.

Mandible (Fig. 7g-j). Right mandible (Fig. 7g): incisor process with 4 teeth, lacinia mobilis with 2 teeth; between lacinia mobilis and pars molaris a row of thick, serrated setae is present; 2 small spines accompanying pars molaris. Left mandible (Fig. 7h): incisor process with 4 teeth, lacinia mobilis with 3 teeth; between lacinia mobilis and pars molaris a row of thick, serrated setae is present; long seta accompanying pars molaris present (not shown in figure); small spines accompanying pars molaris. Proportions of mandibular palp articles (Fig. 7i) 1:2:3 as 1.0:2.0:2.3. Proximal palp article without setae; second article with 5-7 groups of 2-4 setae; distal article with two unequal rows of A setae on the outer side (Fig. 7i) and 5 rows of B setae on inner side (Fig. 7j); 25 $\mathrm{D}$ setae and $4 \mathrm{E}$ setae are present; $\mathrm{C}$ setae absent.

Maxilla I (Fig. 8d). Palp articles ratio (1:2) as 1:3.5, with distal article bearing 8 apical setae. Outer lobe with 7 spines with 1-2 small teeths; inner lobe elongated (3 times longer than wide), with one inner and 4 distal setae.

Maxilla II (Fig. 8c) inner lobe 0.8 times as long as outer lobe; both of them with the apical and subapical species as usual in the genus.
Maxilliped (Fig. 8e-g). Palp (Fig. 8e) distal article 3 with 3 outer setae and two dense rows of distal setae (in apical and inner position); article 4 with two outer setae and 2 very short setae close to the intertion of nail. Outer lobe (Fig. 8f) with 19-20 flattened, thick spines and 9 serrated distal setae, proximal part of inner margin bearing 1 short and 2 long setae. Inner lobe (Fig. 8g) bearing 4 stout apical setae accompanied by 7 serrated setae.

Gnathopod I (Fig. 9a). Coxa 1.75 times wider than long, with 8 short setae on anterior border. Ischiopodite with 11 postero-distal setae. Basipodite short and stout, 1.75 times longer than wide; ischiopodite, meropodite and carpopodite shape and setation as illustrated in Fig. 9a. Propodite with convex, slightly inclined palm, bearing along anterior margin 3 small groups of 2-3 setae each; posterior margin with 6-7 dense groups of setae and a row of 4-5 facial setae close to the insertion of palmar spine; antero-distal group of 8 setae close to the insertion of dactylopodite. Palmar corner with strong palmar spine (Fig. 9b), accompanied by 4 denticulated, thick and short spines. Dactylopodite bearing 4 setae along anterior margin; distal nail as long as one third of dactylopodite.

Gnathopod II (Fig. 9c). Gill elongated, as long as basipodite. Coxa shaped as a rectangular trapezium, protruded in the posterior part; anterior and distal margins with short setae. Gill (epipodite) as long as basipodite. Basipodite elongated, 3.2 times longer than wide; ischiopodite, meropodite

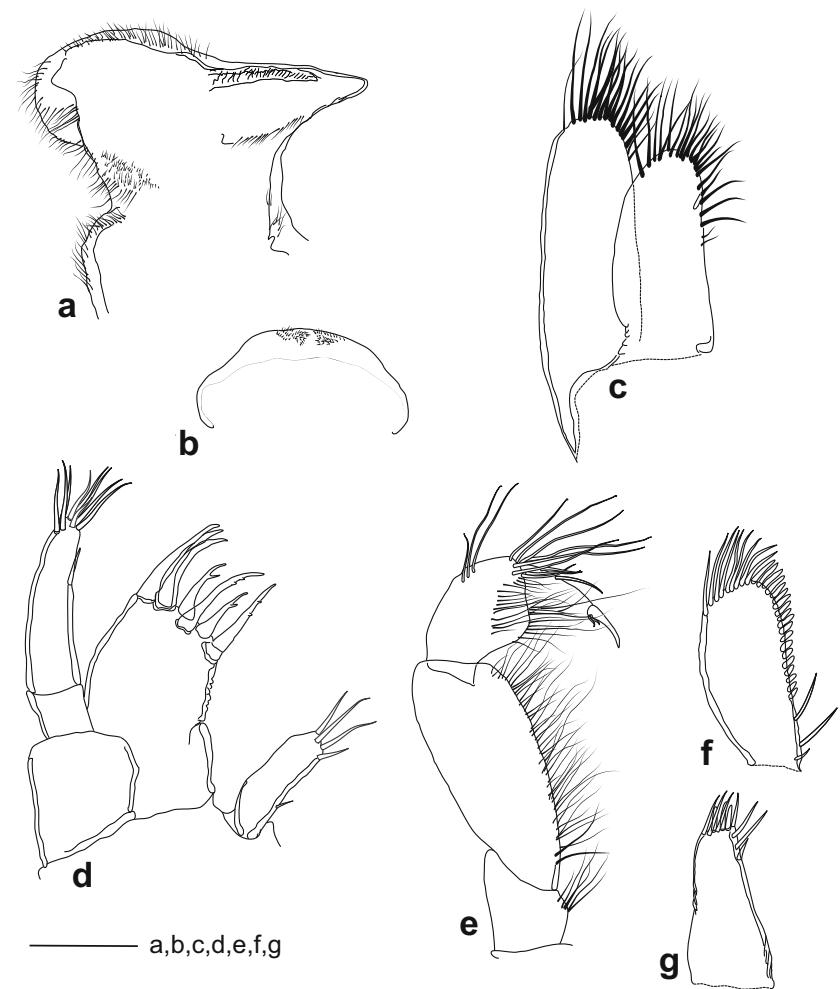

Fig. 8 Niphargus moogi n. sp. holotype male. a Outer lobe of labium; b labrum; c maxilla II; $\mathbf{d}$ maxilla I; e-g maxilliped: palp (e), outer lobe (f) and inner lobe (g). Scale bars, $0.1 \mathrm{~mm}$ 
Fig. 9 Niphargus moogi n. sp. Holotype male. a Gnathopod I; b palmar spine of gnathopod I; c gnathopod II; d pereopod III; e dactylopodite of pereopod III; $\mathbf{f}$ pereopod IV. Scale bars, $0.1 \mathrm{~mm}$

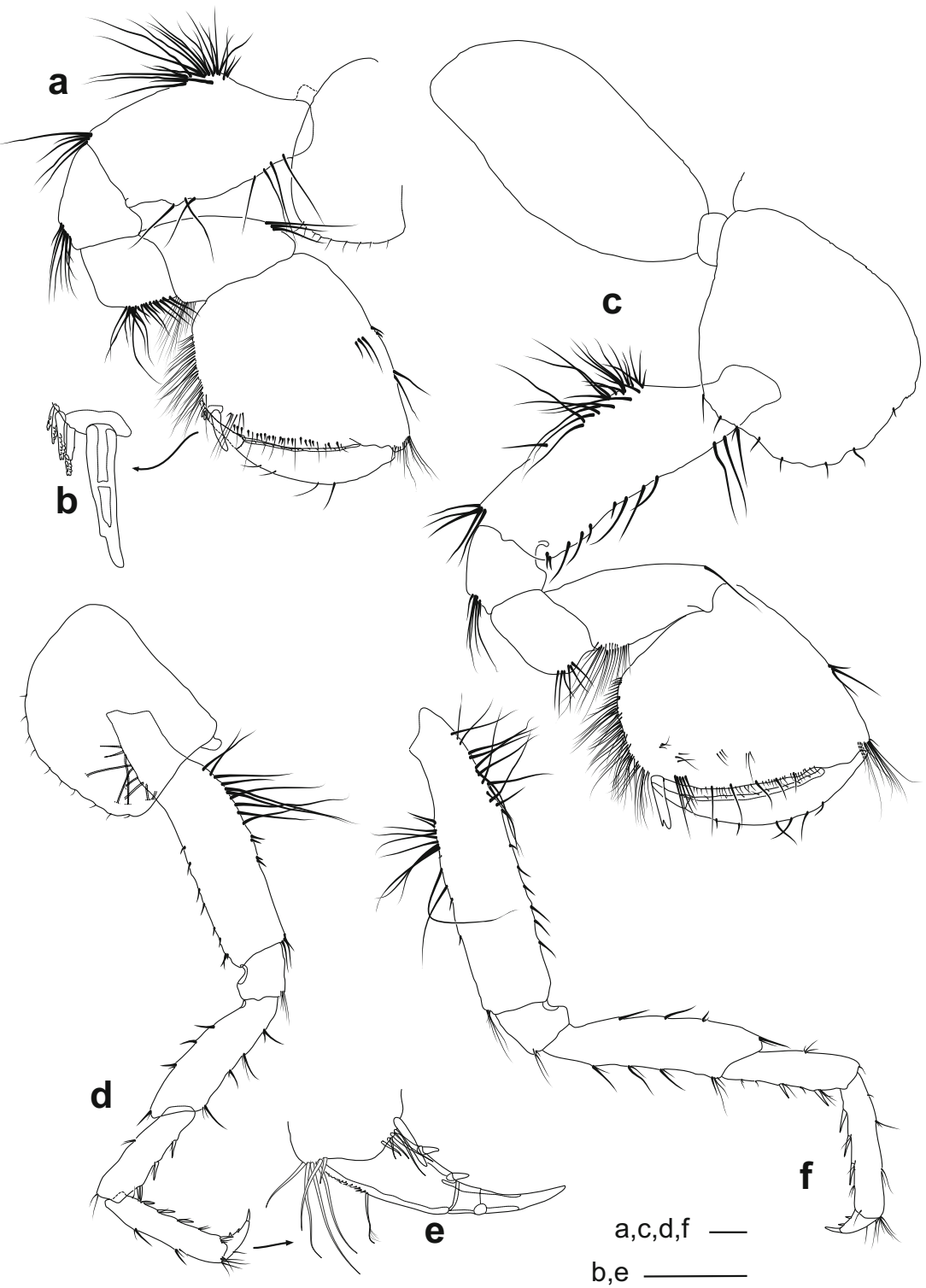

and carpopodite shape and setation as illustrated in Fig. 9c. Propodite 1.2 times longer than propodus of gnathopod I; palm convex and less inclined than palm of gnathopod I, bearing along posterior margin 12 dense rows of setae; anterior margin with a single row of 3 setae and a row of 5 facial setae close to the insertion of palmar spine; antero-distal group of 10 setae close to the insertion of dactylopodite; 4 small rows of sparse facial setae present. Palmar corner with a strong palmar spine accompanied by 2 stout spines. Dactylopodite bearing 6 setae along dorsal margin; distal nail as long as one third of dactylopodite.

Pereopods III-IV (Fig. 9d-f). Pereopods III and IV approximately subequal (ratio III:IV as 1.05:1), shape and setation as in Fig. 9d, f. Dactylopodite IV (Fig. 9e), including nail, about $30 \%$ of propodus IV total length, its nail approximately as long as total dactylus length. Dactylopodites III-IV with a single dorsal plumose seta, and two short and stoud spines on ventral side, the distal one close to the insertion of nail, accompanied by a tiny seta.

Pereopods V-VII (Fig. 10a-c). Proportions of pereopods V:VI:VII as 1.00:1.17:1.27, shape and setation as in Fig. 10ac. Pereopod VII (Fig. 10c) length about $44 \%$ of body length. Coxa V-VI narrow and elongated; coxa $\mathrm{V}$ ratio width:maximum length about 2.2, same proportion in coxa VI about 1.7, both coxae bearing small setae on anterior, posterior and postero-distal margins; coxa VII small, subrounded, $2.5 \mathrm{x}$ wider than long with few marginal setae. Gills (epipodites) on pereopod V and VI as long as coxal width. Basipodites V-VII, with straight or slightly concave posterior margins, without distal lobes; posterior margins with 10-13 short setae; anterior margins with setae accompanied by short spines. Ischiopodites V-VII with a marked notch. 
Fig. 10 Niphargus moogi $\mathrm{n}$. sp. holotype male. a Pereopod VI; b pereopod V; c pereopod VII; d pleopod I with e retinacles magnified. Scale bars, $0.1 \mathrm{~mm}$

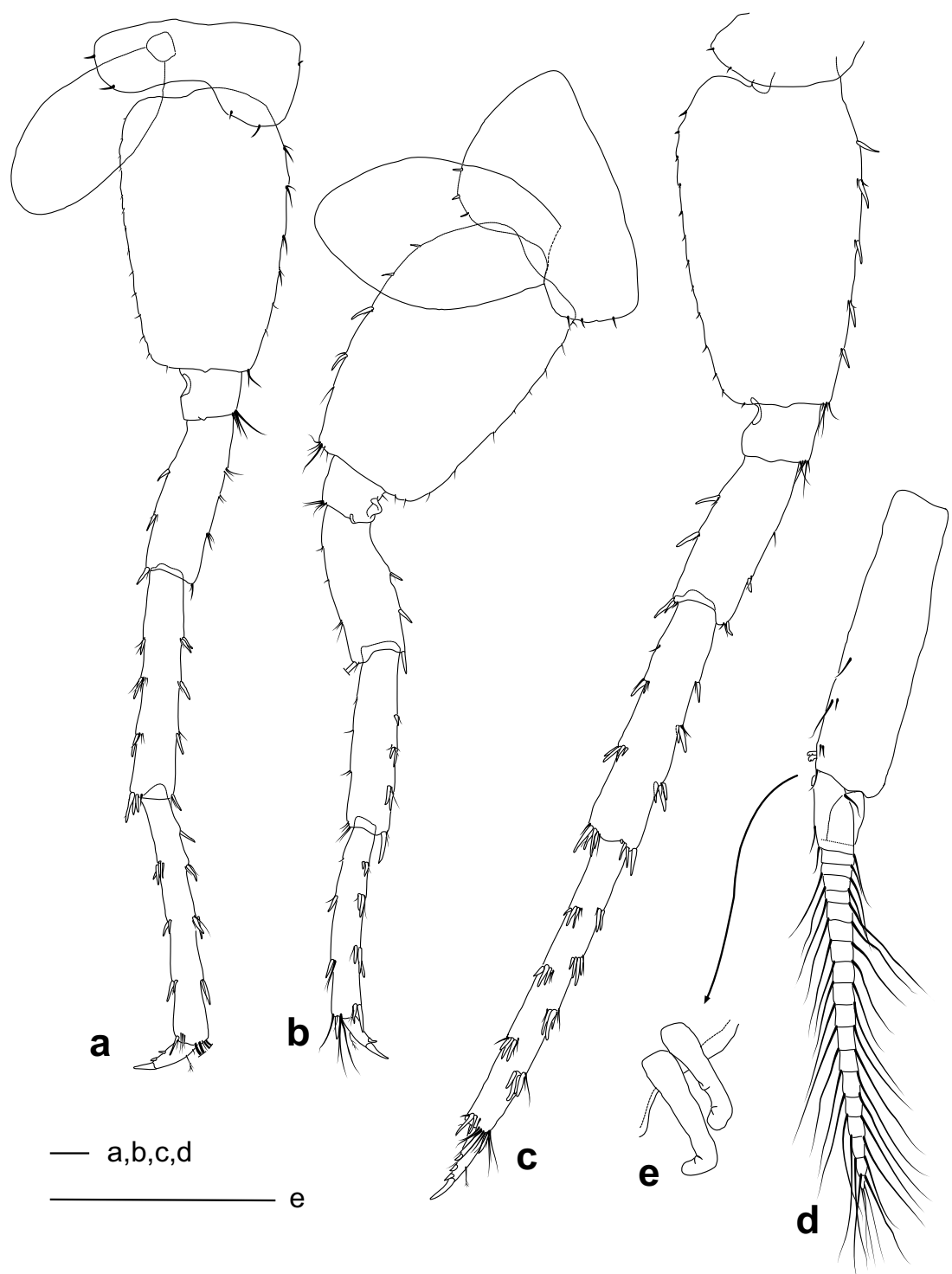

Dactylopodites V-VII with nails length about one third of total dactylus length; dorsal margins with a single plumose seta; ventral margin bearing 2 (dactylopodite s V-VI) and 3 (dactylopodite VII) stout and short spines, the distal ones inserted near dail insertion.

Pleopods (Fig. 10d). Pleopods I-III protopodites (peduncles) with 3-4 groups of postero-distal setae, each group with 1-2 setae and 2 hooked retinacles (Fig. 10d). Rami (exopods and endopods) of 17 articles with 2 long setae each.

Uropods (Fig. 11). Uropod I (Fig. 11b) protopodite with 2 longitudinal rows of 5 dorsal spines and 2 distal spines close to the insertion of exopodite; length ratio endopodite:exopodite as 1.00:0.90, rami quite straight; endopodite with 2 dorsal spines not accompanied by setae and 2 terminal spines and 2 ventral, subapical rows of 5-8 setae each, the distal one close to the insertion of terminal spines; exopodite with 5 dorso- medial spines in three groups (1, 2, 2 spines) accompanied by short rows of setae and 3 terminal spines. Uropod II (Fig. 11c) protopodite with a longitudinal row of 5 spines and three distal spines and a short seta close to the insertion of endopodite and exopodite; endopodite: exopodite length as 1.00:1.25 bearing stout spines as in figure, sometimes accompanied by short setules. Uropod III (Fig. 11a) as long as 67\% of body length; protopodite without lateral setae or spines, 7 apical short spines close to the insertion of endopodite and exopodite; endopodite elongated (2.9 times longer than wide), $94 \%$ of protopodite length, with three lateral short spines accompanied by a small seta, apically with a row of 6 thin setae and no spines; exopodite 2-articulated, very elongated, distal article longer than proximal article (118\%); proximal article with 6 groups of 1-2 plumose, thin setae along inner margin and 2 small setae close to the articulation with distal article, no spines or setae along ventral side present; distal article with 6 
groups of 1-3 thin and short setae along dorsal margin and a tuft of 9 apical setae.

Telson (Fig. 11f). Telson 1.15 times wider than long, cleft $75 \%$ of length; lobes apically widely rounded, each lobe bearing 4 apical spines accompanied by a short, plumose seta; lateral margin with 1 spine and 2 plumose setae (on right ramus accompanied by a short seta); dorsal surface with a stout spine accompanied by a smaller one and, more distally, by two short sensorial setae.

Differential characters of female paratype. Body length $12 \mathrm{~mm}$. Oostegites well developed. Third uropod (Fig. 11d, e) shorter than in male; protopodite (Fig. 11e) 1.8 times longer than wide, bearing distal spines only (1 spine close to the insertion of endopodite and a tuft of 2 spines and 3 setae near the insertion of exopodite); endopodite (Fig. 11e) shorter than in male ( $40 \%$ of protopodite lenfth), 2.1 times longer than wide, with 1 small lateral spine and a tuft of 2 distal spines accompanied by 1 seta of the same length; exopodite proximal article armed with two longitudinal rows of 3-6 groups of short spines and 2 groups of spines close to the insertion of distal article, as in Fig. 11d; distal article armed with a inner longitudinal row of 3 short spines, an outer longitudinal row of 3 tufts of three setae, 1 subapical and e apical setae. Telson (Fig. 11g) with both rami slender than in male; spines more elongated than in male, each ramus bearing 4-6 apical spines accompanied by a short, plumose seta; outer margin with 1 spine and 2 plumosed setae; dorsal surface bearing 1 long and stout spine.

Remarks. The other male paratypes differ mainly in the spinulation of appendages and number of articles of the

Fig. 11 Niphargus moogi $\mathrm{n}$. sp. holotype male. a Uropod III; b uropod I; c uropod II; f telson. Paratype female. d Uropod III; e protopodite and endopodite of uropod III; $\mathbf{g}$ telson. Scale bars, $0.1 \mathrm{~mm}$
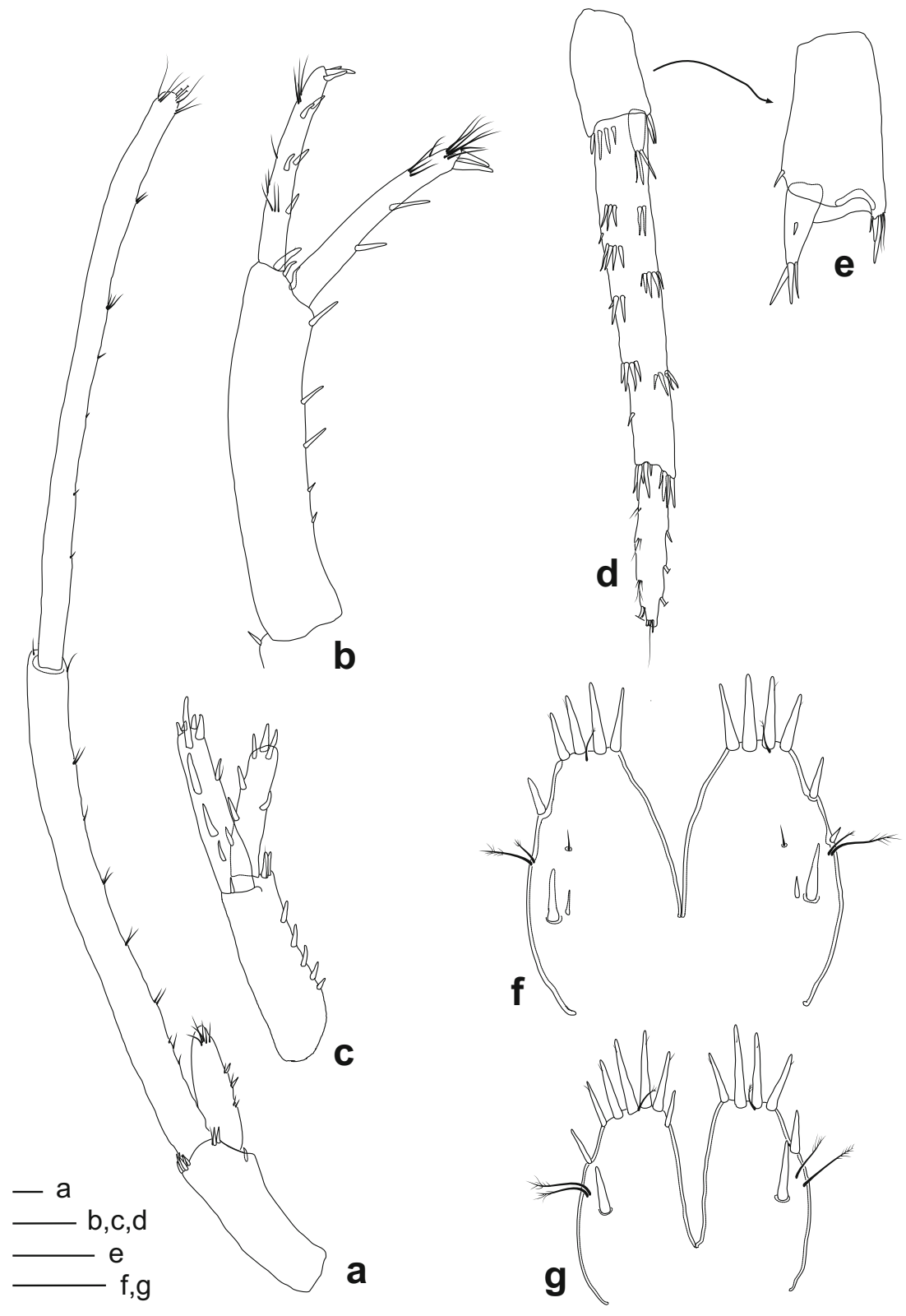
peduncle of antennae I and II. However, given that these individuals are younger than the holotype, such differences may simply be due to age and will not be listed in detail here.

The new species is characterised, with respect to the nonAustrian members of the $N$. tatrensis species complex, by a combination of characters including setation of maxillipeds and setation of palp and outer lobe of maxilla I bearing 4 apical setae (palp of maxilliped with lower number of shorter inner setae and inner lobe of maxilla I with only 2 setae in $N$. scopicauda), number of ventral spines on dactylopodites of pereopods 5-7 (2, 2 and 3 spines, respectively), setation of uropod 3 protopodite (lacking the 6-12 lateral setae present in $N$. scopicauda) and elongation of uropod III endopodite in males (shorter in the other species), shape and armature of telson (larger and stouter than in N. tatrensis and with stouter spines than in $N$. aggtelekiensis, while dorsal spines are absent in N. scopicauda).

Using Schellenberg's (1935) key, the new species is clearly included within the Austrian group but cannot be identified with one of the described forms as it differs especially in the setation of maxilla I and in the three spines on dactylopodite VII (nowhere mentioned in the key). However, these three spines are occasionally present on other species of the complex (Fišer et al. 2010). For this reason, a reliable determination of the new species requires confirmation by sequencing and comparison with the reference sequences deposited in GenBank.

\section{References}

Astrin, J. J., \& Stüben, P. E. (2008). Phylogeny in cryptic weevils: Molecules, morphology and new genera of western Palaearctic Cryptorhynchinae (Coleoptera: Curculionidae). Invertebrate Systematics, 22, 503-522.

Baele, G., Lemey, P., \& Suchard, M. A. (2016). Genealogical working distributions for Bayesian model testing with phylogenetic uncertainty. Systematic Biology, 65(2), 250-264.

Barnard, J. L., \& Barnard, C. M. (1983). Freshwater amphipoda of the world. II. Handbook and bibliography. Hayfield Associates: Mt Vernon, Virginia.

Bouckaert, R. R., \& Drummond, A. J. (2017). bModelTest: Bayesian phylogenetic site model averaging and model comparison. BMC Evolutionary Biology, 17, 1-11.

Bouckaert, R., \& Xie, W. (2016). Ancestral reconstruction/discrete phylogeography with BEAST 2.3.x. tutorial. http://beast2-dev. github.io/beast-docs/beast2/PhylogeographyDiscrete/AR.html. Accessed 29 Jan 2020.

Bouckaert, R., Vaughan, T. G., Barido-Sottani, J., Duchêne, S., Fourment, M., Gavryushkina, A., Heled, J., et al. (2019). BEAST 2.5: An advanced software platform for Bayesian evolutionary analysis. PLoS Computational Biology, 15(4), e1006650.

Brad, T., Fišer, C., Flot, J.-F., \& Sarbu, S. M. (2015). Niphargus dancaui sp. nov. (Amphipoda, Niphargidae) - A new species thriving in sulfidic groundwaters in southeastern Romania. European Journal of Taxonomy, 164, 1-28.

Christian, E., \& Spötl, C. (2010). Karst geology and cave fauna of Austria: A concise review. International Journal of Speleology, 39(2), 71-90.

Coleman, C. O. (2003). "Digital inking": How to make perfect line drawings on computers. Organisms, Diversity and Evolution, Electronic Supplement, 14, 1-14.

Coleman, C. O. (2009). Drawing setae, the digital way. Zoosystematics and Evolution, 85, 305-310.

Copilaş-Ciocianu, D., \& Petrusek, A. (2017). Phylogeography of a freshwater crustacean species complex reflects a long-gone archipelago. Journal of Biogeography, 44, 421-432.

Copilaş-Ciocianu, D., Fišer, C., Borza, P., Balázs, G., Angyal, D., \& Petrusek, A. (2017). Low intraspecific genetic divergence and weak niche differentiation despite wide ranges and extensive sympatry in two epigean Niphargus species (Crustacea: Amphipoda). Zoological Journal of the Linnean Society, 181, 485-499.

Copilaş-Ciocianu, D., Fišer, C., Borza, P., \& Petrusek, A. (2018). Is subterranean lifestyle reversible? Independent and recent largescale dispersal into surface waters by two species of the groundwater amphipod genus Niphargus. Molecular Phylogenetics and Evolution, 119, 37-49.

Delić, T., Stoch, F., Borko, Š., Flot, J.-F., \& Fišer, C. (2020). How subterranean amphipods crossed the Adriatic Sea? Phylogenetic evidence for the dispersal-vicariance interplay mediated by marine regression-transgression cycles. Journal of Biogeography, 47, $1875-1887$.

Dellicour, S., \& Flot, J.-F. (2015). Delimiting species-poor data sets using single molecular markers: A study of barcode gaps, haplowebs and GMYC. Systematic Biology, 64, 900-908.

Dellicour, S., \& Flot, J.-F. (2018). The hitchhiker's guide to single-locus species delimitation. Molecular Ecology Resources, 18, 1234-1246.

Després, L. (2019). One, two or more species? Mitonuclear discordance and species delimitation. Molecular Ecology, 28, 3845-3847.

Doyle, J. J. (1995). The irrelevance of allele tree topologies for species delimitation, and a non-topological alternative. Systematic Botany, 1995(20), 574-588.

Drummond, A. J., \& Bouckaert, R. R. (2015). Bayesian evolutionary analysis with BEAST. Cambridge University Press.

Drummond, A. J., Ho, S. Y. W., Phillips, M. J., \& Rambaut, A. (2006a). Relaxed phylogenetics and dating with confidence. PLoS Biology, 4, e88.

Drummond, A. J., Ho, S. Y. W., Phillips, M. J., \& Rambaut, A. (2006b). Relaxed phylogenetics and dating with confidence. PLoS Biology, 4, 699-710.

Dudich, E. (1932). Biologie der Aggteleker Tropfsteinhöhle "Baradla" in Ungarn. Speläologische Monographien, Wien, 13, 1-246.

Eberle, J., Bazzato, E., Fabrizi, S., Rossini, M., Colomba, M., Cillo, D., Uliana, M., Sparacio, I., Sabatinelli, G., Warnock, R. C. M., Carpaneto, G., \& Ahrens, D. (2019). Sex-biased dispersal obscures species boundaries in integrative species delimitation approaches. Systematic Biology, 68, 441-459.

Eme, D., Westfalls, K. M., Kristjánsson, B. K., \& Pálsson, S. (2017a). Genetic variation of the groundwater amphipod Crangonyx islandicus Svavarsson et Kristjánsson, 2006, endemic to Iceland. Biodiversity Journal, 2017, 8(2), 571-573.

Eme, D., Zagmajster, M., Delić, T., Fišer, C., Flot, J.-F., Konecny-Dupré, L., Pálsson, S., Stoch, F., Zakšek, V., Douady, C. J., \& Malard, F. (2017b). Data from: Do cryptic species matter in macroecology? Sequencing European groundwater crustaceans yields smaller ranges but does not challenge biodiversity determinants. Dryad Dataset. https://doi.org/10.5061/dryad.ns8v4.

Eme, D., Zagmajster, M., Delić, T., Fišer, C., Flot, J.-F., Konecny-Dupré, L., Pálsson, S., Stoch, F., Zakšek, V., Douady, C. J., \& Malard, F. (2018). Do cryptic species matter in macroecology? Sequencing 
European groundwater crustaceans yields smaller ranges but does not challenge biodiversity determinants. Ecography, 41, 424-436.

Esmaeili-Rineh, S., Sari, A., Delić, T., Moškrič, A., \& Fišer, C. (2015). Molecular phylogeny of the subterranean genus Niphargus (Crustacea: Amphipoda) in the Middle East: A comparison with European Niphargids. Zoological Journal of the Linnean Society, $175,812-826$.

Ezard, T., Fujisawa, T., \& Barraclough, T. (2013). R package splits: SPecies' LImits by threshold statistics, version $1.0-18 / \mathrm{r} 45$. Retrieved from http://r-forge.r-project.org/projects/splits/. Accessed 29 Jan 2020.

Fišer, C., Sket, B., \& Trontelj, P. (2008). A phylogenetic perspective on 160 years of troubled taxonomy of Niphargus (Crustacea: Amphipoda). Zoologica Scripta, 37(6), 665-680.

Fišer, C., Coleman, C. O., Zagmajster, M., Zwittnig, B., Gerecke, R., \& Sket, B. (2010). Old museum samples and recent taxonomy: A taxonomic, biogeographic and conservation perspective of the Niphargus tatrensis species complex (Crustacea: Amphipoda). Organisms, Diversity and Evolution, 10, 5-22.

Fišer, C., Gerecke, R., Meisch, C., \& Stoch, F. (2012). Milben (Acari) und Krebstiere (Crustacea). Schriften des Nationalparks Gesäuse, 7, 108-131.

Fišer, C., Pipan, T., \& Culver, D. C. (2014). The vertical extent of groundwater metazoans: An ecological and evolutionary perspective. BioScience, 64, 971-979.

Fišer, C., Alther, R., Zakšek, V., Borko, Š., Fuchs, A., \& Altermatt, F. (2018). Translating Niphargus barcodes from Switzerland into taxonomy with a description of two new species (Amphipoda, Niphargidae). ZooKeys, 760, 113-141.

Flot, J.-F. (2007). Champuru 1.0: A computer software for unraveling mixtures of two DNA sequences of unequal lengths. Molecular Ecology Notes, 7(6), 974-977.

Flot, J.-F. (2010). Vers une taxonomie moléculaire des amphipodes du genre Niphargus: exemples d utilisation de séquences d ADN pour 1 identification des espèces. Bulletin de la Société des sciences naturelles de l'Ouest de la France, 32(2), 62-68.

Flot, J.-F. (2015). Species delimitation's coming of age. Systematic Biology, 64, 897-899.

Flot, J.-F., Tillier, A., Samadi, S., \& Tillier, S. (2006). Phase determination from direct sequencing of length-variable DNA regions. Molecular Ecology Notes, 6, 627-630.

Flot, J.-F., Wörheide, G., \& Dattagupta, S. (2010a). Unsuspected diversity of Niphargus amphipods in the chemoautotrophic cave ecosystem of Frasassi, Central Italy. BMC Evolutionary Biology, 10, 171.

Flot, J. F., Couloux, A., \& Tillier, S. (2010b). Haplowebs as a graphical tool for delimiting species: A revival of Doyle's "field for recombination" approach and its application to the coral genus Pocillopora in Clipperton. BMC Evolutionary Biology, 10(1), 372.

Fritsch, E. (2018). Die Fauna der Gassel-Tropfsteinhöhle. In J. Mattes \& D. Kuffner (Eds.), Höh(l)enluft und Wissensraum: Die GasselTropfsteinhöhle im Salzkammergut zwischen Alltagskultur, Naturkunde und wissenschaftlicher Forschung (pp. 295-304). Linz: Oberösterreichisches Landesmuseum.

Hijonosa, J., Koubinova, D., Szenteczki, M., Pitteloud, C., Dinca, V., Alvarez, N., \& Vila, R. (2019). A mirage of cryptic species: Genomics uncovers striking mitonuclear discordance in the butterfly Thymelicus sylvestris. Molecular Ecology, 28, 3857-3868.

Hoang, D. T., Vinh, L. S., Flouri, T., Stamatakis, A., Von Haeseler, A., \& Minh, B. Q. (2018). MPBoot: Fast phylogenetic maximum parsimony tree inference and bootstrap approximation. $B M C$ Evolutionary Biology, 18, 1-11.

Horton, T., Lowry, J., De Broyer, C., Bellan-Santini, D., Coleman, C. O., Corbari, L., Costello, M. J., et al. (2019). World Amphipoda Database. Niphargus tatrensis Wrzesniovsky, 1888. World
Register of Marine Species. http://www.marinespecies.org/aphia. php?p=taxdetails\&id=546804. Accessed 29 Jan 2020.

Hudec, I., \& Mock, A. (2011). Rozšírenie dvoch druhov rodu Niphargus (Crustacea, Amphipoda) na Slovensku. Slovenský Kras Acta Carsologica Slovaca, 49(2), 153-160.

Jersche, G. (1963). Zur Artfrage und Variabilität von Niphargus tatrensis Wrzesniowski (Ein Beitrag zur postembryonalen Veränderung taxonomischer Merkmale). Zeitschrift für Zoologische Systematik und Evolutionsforschung, 1, 240-276.

Jurado-Rivera, J. A., Álvarez, G., Caro, J. A., Juan, C., Pons, J., \& Jaume, D. (2017). Molecular systematics of Haploginglymus, a genus of subterranean amphipods endemic to the Iberian Peninsula (Amphipoda: Niphargidae). Contributions to Zoology, 86, 239-260.

Kalyaanamoorthy, S., Minh, B. Q., Wong, T. K. F., von Haeseler, A., \& Jermiin, L. S. (2017). ModelFinder: Fast model selection for accurate phylogenetic estimates. Nature Methods, 14, 587-589.

Kapli, T., Lutteropp, S., Zhang, J., Kobert, K., Pavlidis, P., Stamatakis, A., \& Flouri, T. (2016). Multi-rate Poisson tree processes for singlelocus species delimitation under maximum likelihood and Markov chain Monte Carlo. Bioinformatics, 33(11), 1630-1638.

Karaman, G. S. (1993). Crustacea Amphipoda di acqua dolce. Fauna d'Italia, 31, 1-337.

Karaman, G. S., \& Ruffo, S. (1986). Amphipoda: Niphargus-group (Niphargidae sensu Bousfield, 1982). In L. Botosaneau (Ed.), Stygofauna Mundi (pp. 514-534). Leiden: E. J. Brill/Dr. W. Backhuys.

Katoh, K., \& Standley, D. M. (2013). MAFFT multiple sequence alignment software version 7: Improvements inperformance and usability. Molecular Biology and Evolution, 30, 772-780.

Klapyta, P., \& Zasadni, J. (2018). Research history on the Tatra Mountains glaciations. Studia Geomorphologica CarpathoBalcanica, 51(52), 43-85.

Kornobis, E., \& Pálsson, S. (2011). Discordance in variation of the ITS region and the mitochondrial COI gene in the subterranean amphipod Crangonyx islandicus. Journal of Molecular Evolution, 73, 34 44.

Lingafelter, S. W., \& Nearns, E. H. (2013). Elucidating article 45.6 of the international code of zoological nomenclature: A dichotomous key for the determination of subspecific or infrasubspecific rank. Zootaxa, 3709(6), 597-600.

Micherdziński, W. (1956). Taksonomia i ekologia Niphargus tatrensis Wrześniowski 1888 (Amphipoda). Annales Zoologici, 16, 81-134.

Mousseau, T., \& Sikes, D. S. (2011). Almost but not quite a subspecies: A case of genetic but not morphological diagnosability in Nicrophorus (Coleoptera: Silphidae). Biological Journal of the Linnean Society, 102, 311-333.

Munguia, P. (2015). Role of sources and temporal sinks in a marine amphipod. Biology Letters, 11, 20140864.

Nguyen, L. T., Schmidt, H. A., Von Haeseler, A., \& Minh, B. Q. (2015). IQ-TREE: A fast and effective stochastic algorithm for estimating maximum-likelihood phylogenies. Molecular Biology and Evolution, 32, 268-274.

Patten, M. A. (2015). Subspecies and the philosophy of science. The Auk, Ornithological Advances, 132, 481-485.

Pons, J., Barraclough, T. G., Gomez-Zurita, J., Cardoso, A., Duran, D. P., Hazell, S., Kamoun, S., Sumlin, W. D., \& Vogler, A. P. (2006). Sequence-based species delimitation for the DNA taxonomy of undescribed insects. Systematic Biology, 55, 595-609.

Puillandre, N., Lambert, A., Brouillet, S., \& Achaz, G. (2012). ABGD, automatic barcode gap discovery for primary species delimitation. Molecular Ecology, 21(8), 1864-1877.

R Core Team. (2019). R: A language and environment for statistical computing. Vienna: R Foundation for Statistical Computing.

Rambaut, A., Drummond, A. J., Xie, D., Baele, G., \& Suchard, M. A. (2018). Posterior summarization in Bayesian phylogenetics using tracer 1.7. Systematic Biology, 67, 901-904. 
Ronquist, F., Teslenko, M., Van Der Mark, P., Ayres, D. L., Darling, A., Höhna, S., et al. (2012). MrBayes 3.2: Efficient Bayesian phylogenetic inference and model choice across a large model space. Systematic Biology, 61, 539-542.

Schellenberg, A. (1935). Schlüssel der Amphipodengattung Niphargus mit Fundortangaben und mehreren neuen Formen. Zoologischer Anzeiger, 111, 204-211.

Schellenberg, A. (1937). Bemerkungen zu meinem Niphargus-Schlüssel und zur Verbreitung und Variabilität der Arten, nebst Beschreibung neuer Niphargus-Formen. Mitteilungen aus dem Zoologischen Museum in Berlin, 22, 1-30.

Schellenberg, A. (1938). Alters-, Geschlechts- und Individualunterschiede des Amphipoden Niphargus tatrensis f. aggtelekiensis Dudich. Zoologische Jahrbücher, Abteilung für Systematik, Ökologie und Geographie der Tiere, 71, 191-202.

Schwarz, G. (1978). Estimating the dimension of a model. The Annals of Statistics, 6, 461-464.

Seguinot, J., Ivy-Ochs, S., Jouvet, G., Huss, M., Funk, M., \& Preusser, F. (2018). Modelling last glacial cycle ice dynamics in the Alps. The Cryosphere, 12, 3265-3285.

Spöri, Y., \& Flot, J.-F. (2020). HaplowebMaker and CoMa: Two web tools to delimit species using haplowebs and conspecificity matrices. Methods in Ecology and Evolution (accepted).

Straškraba, M. (1972). Les groupements des espèces du genre Niphargus (sensu lato). In Ruffo S. (Ed) Actes du Ier Colloque International sur le Genre Niphargus, Verona 15-16 Avril 1969 (pp. 85-90).

Strouhal, H., \& Vornatscher, J. (1975). Katalog der rezenten Höhlentiere Österreichs. Annalen des Naturhistorischen Museums Wien, 79, 401-542.

Trontelj, P., \& Fišer, C. (2009). Cryptic species diversity should not be trivialised. Systematics and Biodiversity, 7(1), 1-3.
Trontelj, P., Douady, C. J., Fišer, C., Gibert, J., Gorički, Š., Lefébure, T., Sket, B., \& Zakšek, V. (2009). A molecular test for cryptic diversity in ground water: How large are the ranges of macro-stygobionts? Freshwater Biology, 54, 727-744.

Verovnik, R., Sket, B., \& Trontelj, P. (2005). The colonization of Europe by the freshwater crustacean Asellus aquaticus (Crustacea: Isopoda) proceeded from ancient refugia and was directed by habitat connectivity. Molecular Ecology, 14, 4355-4369.

Villesen, P. (2007). FaBox: An online toolbox for fasta sequences. Molecular Ecology Notes, 7, 965-968.

Vornatscher, J. (1952). Bemerkungen zur Tierwelt der Peggauer Lurhöhle. Die Höhle, 3, 10-14.

Weber, D., Flot, J. F., Weigand, H., \& Weigand, A. M. (2020). Demographic history, range size and habitat preferences of the groundwater amphipod Niphargus puteanus (C.L. Koch in Panzer, 1836). Limnologica, 82. https://doi.org/10.1016/j.limno.2020. 125765.

Winterberg, S., \& Willett, S. D. (2019). Greater Alpine river network evolution, interpretations based on novel drainage analysis. Swiss Journal of Geosciences, 112, 3-22.

Wrzešniowski, A. (1888). Über drei unterirdische Gammariden. Zeitschrift für Wissenschaftliche Zoologie, 50, 600-724.

Yu, Y., Harris, A. J., Blair, C., \& He, X. J. (2015). RASP (reconstruct ancestral state in phylogenies): A tool for historical biogeography. Molecular Phylogenetics and Evolution, 87, 46-49.

Zhang, J., Kapli, P., Pavlidis, P., \& Stamatakis, A. (2013). A general species delimitation method with applications to phylogenetic placements. Bioinformatics, 29, 2869-2876.

Publisher's note Springer Nature remains neutral with regard to jurisdictional claims in published maps and institutional affiliations. 